\title{
Formation of starch in plant cells
}

\author{
Barbara Pfister $^{1} \cdot$ Samuel C. Zeeman ${ }^{1}$
}

Received: 21 April 2016/Accepted: 22 April 2016/Published online: 11 May 2016

(C) The Author(s) 2016. This article is published with open access at Springerlink.com

\begin{abstract}
Starch-rich crops form the basis of our nutrition, but plants have still to yield all their secrets as to how they make this vital substance. Great progress has been made by studying both crop and model systems, and we approach the point of knowing the enzymatic machinery responsible for creating the massive, insoluble starch granules found in plant tissues. Here, we summarize our current understanding of these biosynthetic enzymes, highlighting recent progress in elucidating their specific functions. Yet, in many ways we have only scratched the surface: much uncertainty remains about how these components function together and are controlled. We flag-up recent observations suggesting a significant degree of flexibility during the synthesis of starch and that previously unsuspected nonenzymatic proteins may have a role. We conclude that starch research is not yet a mature subject and that novel experimental and theoretical approaches will be important to advance the field.
\end{abstract}

Keywords Arabidopsis thaliana - Amylopectin · Amylose · Protein phosphorylation .

Protein complex formation

$\begin{array}{ll}\text { Abbreviations } & \\ \text { AA } & \text { Amino acid } \\ \text { ADPglucose } & \text { Adenosine 5'-diphosphate-glucose } \\ \text { AGPase } & \text { ADPglucose pyrophosphorylase } \\ \text { BE } & \text { Branching enzyme }\end{array}$

Samuel C. Zeeman

szeeman@ethz.ch

1 Department of Biology, ETH Zurich, 8092 Zurich, Switzerland

$\begin{array}{ll}\text { CBM } & \text { Carbohydrate-binding module } \\ \text { CLD } & \text { Chain-length distribution } \\ \text { DBE } & \text { Debranching enzyme } \\ \text { DP } & \text { Degree of polymerization } \\ \text { Glc-1-P } & \text { Glucose-1-phosphate } \\ \text { Glc-6-P } & \text { Glucose-6-phosphate } \\ \text { GBSS } & \text { Granule-bound starch synthase } \\ \text { GT } & \text { Glycosyltransferase } \\ \mathrm{P}_{\mathrm{i}} & \text { Orthophosphate } \\ \text { PP } & \text { Pyrophosphate } \\ \mathrm{SS} & \text { Starch synthase }\end{array}$

\section{Introduction}

Starch is an insoluble, non-structural carbohydrate composed of $\alpha$-glucose polymers. It is synthesized by plants and algae to store energy in a dense, osmotically inert form. Starch has significant value for humans: it serves as the main carbohydrate source in an equilibrated diet and as a renewable raw material for industry. For instance, starch is extensively used as a thickener and texturizer in processed foods, as it gelatinizes to form pastes when heated in water. Starch pastes also have innumerable uses in the non-food sector, such as in the production of paper and board [1, 2], of biodegradable plastics and packaging materials [3] amongst others.

Based on its biological functions, starch is often categorized into two types: transitory starch and storage starch. The starch which is synthesized in the leaves directly from photosynthates during the day is typically defined as transitory starch, since it is degraded in the following night to sustain metabolism, energy production and biosynthesis in the absence of photosynthesis. If this 
night-time carbohydrate supply is reduced-for instance in mutants impaired in starch synthesis-plants grow more slowly and experience acute starvation [4]. The starch in non-photosynthetic tissues, such as seeds, stems, roots or tubers, is generally stored for longer periods and regarded as storage starch. Remobilization takes place during germination, sprouting or regrowth, again when photosynthesis cannot meet the demand for energy and carbon skeletons for biosynthesis. Also mutants with perturbation in storage starch biosynthesis are often disadvantaged, and mutant seeds with low or no starch may even be inviable [5, 6]. It is this storage starch that we consume as our food and extract for industrial uses-it can account for $70-80 \%$ of the dry weight in wheat grains and cassava roots $[7,8]$.

Starches from different botanical sources vary in terms of their functional properties (e.g., gelatinization onset temperature, final viscosity of paste, formation of twophase pastes or paste stickiness) and thus in their end-uses. This variation stems from differences in the structure of starch, such as the size of starch granules, their composition, and molecular architecture of the constituent polymers [9]. Still, extracted starch often needs to be modified using costly and sometimes waste-generating chemical, physical or enzymatic treatments to confer or enhance the required functional properties [10]. Starch structure also influences its digestibility in the gut. Those with reduced digestibility (resistant starch), such as highamylose starches, are increasingly valued due to their health-promoting effects, potentially serving as a preventive measure against conditions such as colorectal cancer and diabetes [11]. Understanding starch biosynthesis and its relationships to structure and functionality is of enormous interest as it represents a prerequisite for the targeted improvement of starch crops.

This review focuses on the mechanisms of starch biosynthesis and seeks to provide a broad overview of our current knowledge, while highlighting recent advances. Significant steps in our basic knowledge have been made through the analyses of model systems such as the plant Arabidopsis thaliana and the single-celled green alga $\mathrm{Ch}$ lamydomonas reinhardtii. Although their starches have no direct industrial value, many aspects of starch biosynthesis appear to be widely conserved within the Viridiplantae clade. Thus, discoveries made in these systems are likely to have broad relevance. It is nevertheless always important to bear in mind the cellular and metabolic context in which starch is made. Variation in conditions between tissues and species can have a strong influence on the amount and structure of starch. Such differences may explain why, in some cases, different phenotypes result from similar genetic perturbations. In the long run it will be important to understand both the basic starch-biosynthetic process and tissue-specific factors that affect it.

\section{The structure of starch}

Starch consists of the two glucose polymers amylopectin and amylose, which together form insoluble, semi-crystalline starch granules (Fig. 1; see [12] for a comprehensive review). Both polymers are made of $\alpha$-1,4-linked glucan chains connected with $\alpha-1,6$-branch points, but their structure and biosynthesis are distinct. Amylopectin accounts for 75-90 \% of wild-type starches, has a degree of polymerization (DP) of $\sim 10^{5}$ and a branching level of 4-5\% (i.e., $4-5 \%$ of its linkages are $\alpha-1,6$-branch points) [13]. Amylopectin makes up the structural framework and underlies the semi-crystalline nature of starch. Amylose is considerably smaller and only lightly branched [13]. It is believed to fill spaces in the semi-crystalline matrix formed by amylopectin, probably rendering the starch granule denser.

The relatively simple chemical nature of starch is in stark contrast to the structural complexity of the final starch granule. This chemical simplicity makes it difficult to obtain definitive structural information about the glucans. Instead, the techniques used to determine the abundance of structural units (e.g., numbers of branch points or chain lengths) tend to deliver average measures that mask structural heterogeneity. Such limitations mean that we rely on structural models of starches. Inevitably this can impact on the interpretation of data, such as substrate preferences of enzymes or mutant phenotypes, and affects our ability to unambiguously ascribe specific enzyme functions. Still, for many enzymes, data of different types have helped to build a consensus view of their role in starch synthesis.

\section{Molecular structure of amylopectin}

It is generally accepted the branching frequency and pattern in amylopectin is non-random. Within each molecule, the constituent chains are categorized according to their connection to other chains: A-chains are the external chains that carry no branches themselves while B-chains are those that carry one or more branches. The $\mathrm{C}$-chain is the single B-chain chain per molecule having a free reducing end. In the models of amylopectin, the branch points are concentrated in certain regions from which the linear chains segments extend to form clusters (Fig. 1). The frequency distribution of chain lengths (chain-length distributions or CLDs), deduced from the analysis of debranched starches, shows that most chains are of between 10 and 20 glucose 
A Glucose-1-phosphate

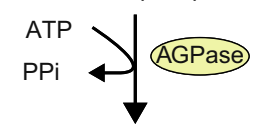

ADPglucose

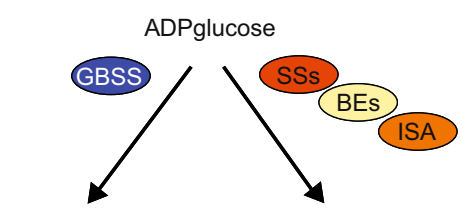

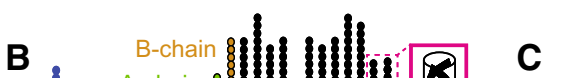

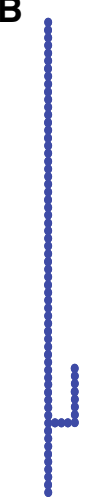

Amylose

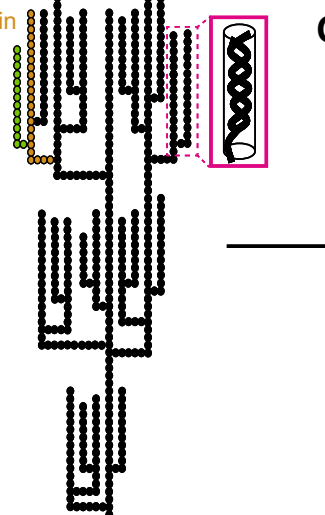

Amylopectin

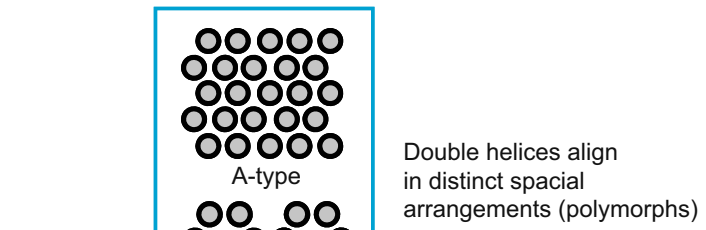

in distinct spacial

arrangements (polymorphs)

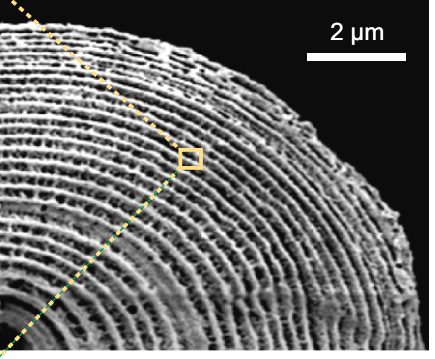

Internal growth-ring structure of a starch granule (after chemical/enzymatic treatment)
Fig. 1 The structure and biosynthesis of starch. a Overview of the core starch biosynthesis pathway. ADPglucose pyrophosphorylase (AGPase) produces ADPglucose, the substrate of starch synthases (SSs). Granule-bound starch synthase (GBSS) synthesizes amylose, while soluble SSs, branching enzymes (BEs) and isoamylase-type debranching enzyme (ISA) collectively synthesize amylopectin. b Molecular structure of amylose and amylopectin (according to the cluster model), showing its branching pattern and formation of secondary structures. Filled, joined circles represent individual glucosyl residues. c High-order alignment of amylopectin double helices. Each growth ring (right) has a thickness of ca. 200-400 nm and contains a semi-crystalline region and an amorphous region. The semi-crystalline region consists of alternating crystalline lamellae (containing the linear parts of the chains) and amorphous lamellae (containing most of the branch points) which stack with a periodicity of 9-10.5 nm (middle). Depending on the exact architecture of the amylopectin giving rise to the clusters, the double helices either arrange as densely packed A-type polymorph or less dense hexagonal B-type polymorph (top). A mixture of A and B is also possible and named C-type polymorph (not shown). Figure composed using parts from [30] (with permission from Elsevier) and [284] (thearabidopsisbook.org; Copyright American Society of Plant Biologists) units. These are considered to be the $\mathrm{A}$ - and $\mathrm{B}_{1}$-chains (B-chains that participate in the formation of one cluster). However, there are also longer chains, which are thought to form connections between different clusters. These are generally believed to be oriented in the same orientation as the cluster-filling $\mathrm{A}-$ and $\mathrm{B}_{1}$-chains (cluster model $[14,15]$ ) and assigned as $\mathrm{B}_{2^{-}}, \mathrm{B}_{3^{-}}, \mathrm{B}_{4^{-}}$-chains for chains spanning two, three or four clusters, respectively; [16]. They could, however, also be oriented perpendicularly to the clusters (backbone model [17]).

X-ray scattering and electron microscopic analyses suggest that clusters stack with a periodicity of $\sim 9-10 \mathrm{~nm}$ $[18,19]$. X-ray diffraction patterns further reveal that the neighboring linear chain segments within clusters form parallel double helices, with each complete turn having 6 glucose units per chain and a period of $2.1 \mathrm{~nm}$. The double helices align in the dense A-type polymorph or the less dense (and more hydrated) B-type polymorph [20, 21] (Fig. 1c). Starches containing mixtures of A- and B-type polymorphs are also observed and named C-type polymorph. A-type polymorphs are typical of cereal grains and B-type polymorphs of tuber starches. The factors responsible for determining the polymorph type are not fully understood, however.

\section{High-order structures of starch}

Various microscopic analyses suggest levels of organization beyond the 9-nm-repeat (Fig. 1c). Some of the earliest drawings and light micrographs of starch granules showed concentric layers within the granules. These were called 'growth rings' due to the superficial similarity in 
appearance to the growth rings of trees. Treating cracked starch granules with $\alpha$-amylase or acid, which removes the less crystalline regions, and analysis with scanning electron microscopy clearly reveal growth rings as a repeating layered structure with a period of a few hundred nanometers. Each of these resistant layers is thought to be composed of numerous 9-nm-repeats. The susceptible amorphous region is presumed to have a lower degree of order [22]. In addition to the growth ring structure, spherical blocklets with a diameter between 20 and $500 \mathrm{~nm}$ have been observed in the semi-crystalline regions of starches [23]. These might represent a left-handed amylopectin super-helix, which was proposed by Oostergetel and van Bruggen [24] based on electron optical tomography and cryo electron diffraction analyses. While some of the structural features of starch are widely accepted, such as the formation and packing of double helices and the presence of growth rings, others remain less well understood. The potential introduction of artefacts during sample preparation for many of the techniques applied needs to borne in mind.

Starch granules from different species and tissues vary greatly in size and shape, ranging from relatively small particles of $0.5-2 \mu \mathrm{m}$ in diameter in amaranth seeds and flat disks in Arabidopsis leaves to smooth spheres of up to $100 \mu \mathrm{m}$ in tuberous roots [25, 26]. Granules contain small amounts of protein (typically $0.1-0.7 \%$ ), which is mostly the granule-bound starch synthase (GBSS) that makes amylose, but also other amylopectin synthesizing enzymes, such as other starch synthases (SSs) and starch-branching enzymes (BEs) [27, 28]. Many starches further contain traces of lipids and phosphate groups (covalently linked at the C6 or C3 position of glucose) [27]. The phosphorylation level of cereal starches is extremely low. In Arabidopsis leaf starch it is around $0.05 \%$ (i.e., around one per 2000 glucose units is phosphorylated), while in tuber starches it can be many times higher ( $\sim 0.5 \%$ in potato). Phosphorylation appears to be confined to amylopectin and enriched in the amorphous regions [29]. A high phosphate content is an industrially relevant trait as it is associated with an increased granule hydration and lowered crystallinity, yielding starch pastes with higher transparency, viscosity and freeze-thaw stability ([30] and references therein).

\section{The enzymes of starch biosynthesis}

Starch is synthesized in the plastids-chloroplasts in leaves or specialized amyloplasts in the starch-storing tissues of staple crops. In red algae and glaucophytes, the situation is different; their so-called floridean starch is synthesized in the cytosol via a pathway which appears to be mechanistically different from that in plants and green algae $[31,32]$. Starch synthesis in plants involves three major enzyme activities: First, SSs elongate the non-reducing ends of glucose chains using adenosine $5^{\prime}$ diphosphate-glucose (ADPglucose) as glucosyl donor; second, BEs create branches from existing chains via glucanotransferase reactions; and third, debranching enzymes (DBEs) hydrolyze some of the branches again (Fig. 1a). Although presented in a sequential manner, it is important to perceive it as a simultaneous, interdependent process. The starch-biosynthetic enzymes are well conserved between different plant species, suggesting a common origin [33]. The basic mechanism of starch biosynthesis resembles that of glycogen, the water-soluble $\alpha-1,4$ and $\alpha-1,6$-linked glucose polymer synthesized in many bacteria, fungi and animals. However, as described below, there is more complexity in starch biosynthesis in terms of duplication and specialization of SSs and BEs, the recruitment of additional enzymes (i.e., DBEs) and other recently described proteins that may contribute to the formation of the semi-crystalline starch granule.

\section{ADPglucose pyrophosphorylase (AGPase) provides the substrate for starch biosynthesis}

Starch synthesis starts with the production of ADPglucose, the substrate for SSs. In photosynthetically active chloroplasts of leaves, the generation of ADPglucose is directly linked to the Calvin-Benson cycle through conversion of fructose-6-phosphate to glucose-6-phosphate (Glc-6-P) (catalyzed by phosphoglucose isomerase) through to glucose-1-phosphate (Glc-1-P) (catalyzed by phosphoglucomutase). AGPase (EC 2.7.7.27) then catalyzes the conversion of Glc-1-P and ATP to ADPglucose and pyrophosphate $\left(\mathrm{PP}_{\mathrm{i}}\right)$. Via this pathway approximately $30-50 \%$ of photoassimilates of Arabidopsis leaves are partitioned into starch [34]. Each of the aforementioned reactions is thermodynamically reversible. However, in vivo, the $\mathrm{PP}_{\mathrm{i}}$ product of the last reaction is further metabolized by plastidial alkaline pyrophosphatase, hydrolyzing it to yield two molecules of orthophosphate $\left(P_{i}\right)[35,36]$. This renders the synthesis of ADPglucose in the chloroplast essentially irreversible. Indeed, Arabidopsis mutants deficient in SSIV (described below), which are unable to utilize ADPglucose for starch synthesis, display a strong impact on photosynthetic metabolism, attributed to the accumulation of ADPglucose and the consequential depletion of the adenylate pool [37].

The synthesis of ADPglucose is similar in heterotrophic tissues where sucrose is imported from source tissues and metabolized to produce hexose phosphates in the cytosol. For starch biosynthesis, both hexose phosphates (typically Glc-6-P, although Glc-1-P transport has also been 
reported) and ATP are transported into the amyloplast to serve as substrate for the synthesis of ADPglucose [38, 39]. Hexose phosphate transport occurs in exchange for $P_{i}$, while ATP transport occurs in exchange for ADP and $\mathrm{P}_{\mathrm{i}}$. In the cereal endosperm, the pathway differs: here the major AGPase activity is found in the cytosol and ADPglucose is imported directly into the plastid via a dedicated, cereal-specific subclass of adenine nucleotide transporter [40-43].

The synthesis of ADPglucose by AGPase is often regarded as the "committed step" of starch synthesis. There is appreciable evidence that the step is regulated both at the transcriptional and post-translational levels, which has been reviewed in detail elsewhere [44]. Briefly, AGPase is a heterotetramer consisting of two large regulatory subunits and two small catalytic subunits. In many cases, the enzyme has been demonstrated to be allosterically activated by 3-phosphoglycerate and inhibited by $\mathrm{P}_{\mathrm{i}}$ (e.g. [45, 46]). The enzyme is furthermore sensitive to redox regulation via the reduction of a intermolecular disulfide bridge that forms between cysteine residues of the small subunit [47-49]. Together, these regulatory features are thought to ensure that ADPglucose, and thus starch, is only made when there are sufficient substrates. Many attempts have been made to promote the flux towards starch by expressing unregulated AGPase from Escherichia coli or planta (e.g., [50-57]). This has resulted in increased starch content in at least one potato variety [50], increased overall grain yield in maize $[52,56]$ and wheat [53] and increased tuberous root biomass in cassava [55] (reviewed in [58]).

Although the above-mentioned pathway of ADPglucose production is well accepted, other mechanisms for the production of ADPglucose have been proposed (see [34] and references therein). These alternate pathways, however, require validation.

\section{The domain structure of starch synthases (SSs)}

SSs (ADPglucose:1,4- $\alpha$-D-glucan 4- $\alpha$-D-glucosyltransferases; EC 2.4.1.21) belong to the glycosyltransferase (GT) family 5 (CAZy [59]). They catalyze the transfer of the glucosyl moiety of ADPglucose to the non-reducing end (here the $\mathrm{C} 4$ position) of an existing glucosyl chain, creating an $\alpha-1,4$ bond and elongating the chain. Five SS classes are involved in starch biosynthesis: four are soluble in the stroma (or partially bound to the granule) and one is almost exclusively granule bound. The soluble SSs (SSI, SSII, SSIII and SSIV) are involved in amylopectin synthesis while the granule-bound SS (GBSS), is responsible for amylose synthesis. There is an additional putative SS class named SSV that is related in sequence to SSIV but has not yet been functionally characterized [60].
SSs consist of a highly conserved C-terminal catalytic domain and a variable N-terminal extension (Fig. 2). The catalytic domain is conserved between SSs and bacterial glycogen synthases, which also use ADPglucose as substrate, and contains both a GT5 and a GT1 domain (CAZy; [61]). According to the crystal structures of Agrobacterium tumefaciens and $E$. coli glycogen synthases, the rice GBSSI and barley SSI, the catalytic domain adopts a GT-B fold, with the active site in a cleft between the two GT domains [62-65]. Binding of ADPglucose probably involves one or more conserved Lys-X-Gly-Gly motifs [66-68] and other conserved charged/polar residues [62, 69-72]. The N-terminal extensions of SS classes are dissimilar. In the case of SSIII and SSIV, these extensions were shown to be involved in protein-protein interactions, potentially via conserved coiled-coil motifs [73-75]. The N-terminal part of SSIII also contains three conserved carbohydrate-binding modules (CBMs) that are involved in substrate binding [76, 77].

Gene duplications have resulted in multiple isoforms of some enzymes. The encoded proteins have a high degree of sequence similarity but are often differentially expressed, with specific isoforms predominating in the endosperm or vegetative tissues [78-84]. For example, several isoforms exist for each SS class in cereals (except for SSI and SSV). The "a" isoforms of SSII and SSIII appear to be the predominant isoforms in the endosperm, based on expression and mutant studies (hereafter, we refer to these "a" isoforms of SSII and SSIII unless otherwise stated). In other species, including Arabidopsis and plants having storage starch-filled organs (e.g. potato), there is only one isoform for each class.

\section{Granule-bound starch synthase (GBSS) synthesizes amylose}

Mutants with reduced or no GBSS activity, so-called waxy lines, typically produce less or no amylose, respectively, for instance in the endosperms of maize [85, 86], rice [87, 88], wheat [89], barley [90] and amaranth [91], cassava roots [8], potato [92, 93], pea seeds [94], Arabidopsis leaves [95] and C. reinhardtii [96, 97]. This suggests that GBSS is responsible for the synthesis of amylose and that no other synthase can replace it in this function.

It is likely that GBSS synthesizes amylose within the granular matrix formed by amylopectin. Monitoring the distribution of amylose over time in potato lines in which GBSS expression and amylose contents were repressed to low levels, suggested that amylose was more apparent toward the center of the starch granule and that this amylose-containing core grows together with the granule [98]. It is important to realize that although insoluble, the granule is hydrated and small molecules such as ADPglucose can apparently diffuse into the matrix and be used by granule- 


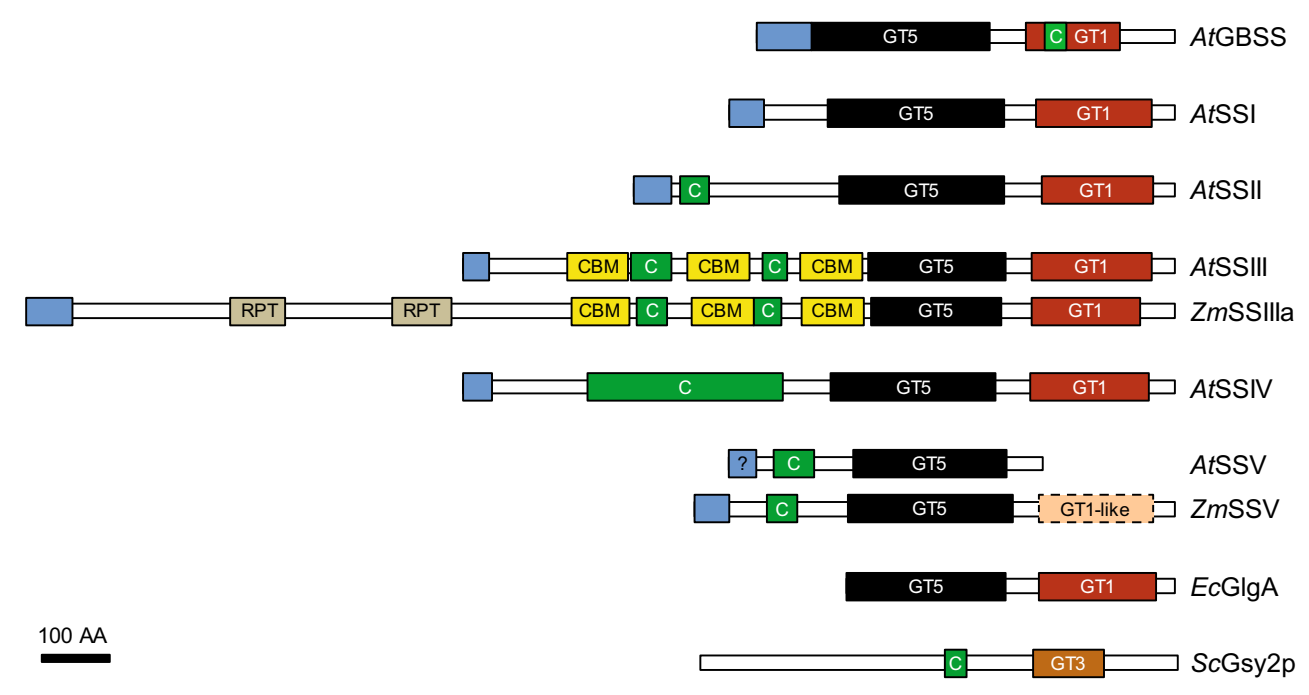

Fig. 2 The domain structure of starch synthase (SS) classes. SSs from Arabidopsis $(A t)$ compared with glycogen synthases from $E$. coli $(E c)$ and budding yeast $(S c)$. Maize $(\mathrm{Zm})$ SSIIIa and SSV are included as they differ in their structures compared with the Arabidopsis orthologs. Shown are plastidial transit peptides (N-terminal blue boxes), internal repeats (gray boxes, RPT), carbohydrate-binding modules of family 25 (yellow boxes, CBM), coiled-coil domains (green boxes, C), glycosyltransferase-5 domains (black boxes, GT5), glycosyltransferase-1 domains (red boxes, GT1) and a glycosyltransferase-3 domain (orange box, GT3). Transit peptides were predicted with ChloroP [285], coiled-coil motifs with Paircoil2 ([286]; $p$ value $<0.05,21$ amino acids minimal length) and all other motifs with SMART. Note that the domain length and annotation depend on the database queried. For example, the GT3 domain of $S c$ Gsy2P is

bound proteins [99]. There is in vitro evidence that GBSS acts in a processive rather than distributive manner, preferentially adding glucose units to the same chain instead of switching between chains [68, 99]. GBSS activity also strongly increased when assayed in amylopectin concentrations high enough for spontaneous glucan crystallization to occur [68]. Thus, GBSS may synthesize amylose by elongating individual glucan chains in the environment surrounding crystalline or crystallizing amylopectin. Its product probably is well protected from branching activity, explaining why it is largely linear. The nature of the primer used for amylose synthesis is not fully resolved. Radiolabeling of $C$. reinhardtii starch granules suggested that GBSS first elongates amylopectin chains and then releases these chains to the amylose fraction [100]. This may be different in vascular plants, however, as no transfer of radioactive label from amylopectin to amylose was observed in Arabidopsis [101]. Another primer could be malto-oligosaccharides, the presence of which was shown to increase GBSS activity and increase its specificity toward amylose synthesis (as opposed to the elongation of amylopectin chains) both in vitro [102] and in vivo [101].

Although being almost completely granule bound [103], GBSS does not contain any predicted starch-binding identified as a GT1 domain by SMART and was manually re-assigned as GT3 here [287]. Whereas $S c$ Gsy2p is a GT3 family glycosyltransferase and uses UDPglucose as substrate, all other shown synthases are GT5 family glycosyltransferases and use ADPglucose as substrate. The N-terminal regions of SSIII containing the coiled-coil motifs and CBMs are highly conserved among various orthologs, but further contain internal repeats in some cases (e.g., in barley and wheat SSIIIa). Orthologs of SSII often showed weaker or no coiledcoil predictions. AtSSV has a weakly predicted chloroplast transit peptide, but lacks the GT1 domain and is of unknown function. SSV from most other species, however, have a C-terminal extension including a stretch that was designated as a putative GT1-like domain [60]. Bar 100 amino acids (AA)

domains (Fig. 2). Recently, a conserved starch-binding protein equipped with a CBM of family 48 and a long coiled-coil motif [104] was shown to interact with Arabidopsis GBSS via a short coiled-coil motif on GBSS [95]. This interaction was required both for efficient granule binding of GBSS and for amylose synthesis.

Evidence suggests that GBSS also contributes to amylopectin synthesis. In some studies of waxy mutants, amylopectin structure was reported to be slightly altered [91, 105-108], whereas in other studies-sometimes on the same species-it appeared normal [109-111]. A notable exception is $C$. reinhardtii where the lack of GBSS caused an alteration in amylopectin structure: C. reinhardtii contains a low-molecular weight fraction of amylopectin with iodine-staining characteristics intermediate between those of amylopectin and amylose, which was missing in GBSS mutants [96]. The distinctive function of $C$. reinhardtii GBSS compared with GBSSs from vascular plants may be explained by the presence of a unique C-terminal tail and the several-fold higher specific activity [112]. Interestingly, the C. reinhardtii double mutant deficient in SSIII and GBSS was much more affected than each single mutant as it produced only small amounts of mostly water-soluble glucan that was almost 
devoid of chains with a (DP higher than 40 [97, 113]. Also early work on potato tuber starch synthesis provided evidence for a potential role for GBSS in starch synthesis. In ssIII repressor lines, in which GBSS was up-regulated, amylopectin had a population of extra-long chains and starch granules were altered in morphology [114]. Both traits are likely to result from the (increased) GBSS activity, as they were abolished when GBSS activity was repressed simultaneously with SSIII.

\section{The core amylopectin synthesis: starch synthases SSI to SSIII}

Based on mutant phenotypes, each SS class appears to have a distinct role during amylopectin synthesis: put simply, SSI and SSII are thought to produce the short singlecluster-filling chains (i.e., the $\mathrm{A}$ - and $\mathrm{B}_{1}$-chains) while SSIII is proposed to synthesize longer cluster-spanning B chains [115]. In contrast, SSIV appears to be less involved in the determination of amylopectin structure but to function in starch granule initiation and the control of granule morphology [116-118]. However, in reality the situation is more complicated: there are instances of functional overlap between enzymes [119], interferences in biosynthesis by starch degradative enzymes [120-122], and of complex formation between enzymes [73, 74, 123-127]. In addition, there are sizeable gaps in our fundamental understanding of how each class fulfils its proposed role at the molecular level, as described in the following sections.

The relative contribution of each SS class varies in different tissues and between species, which is believed to account at least partially for the structural variation between starches from different sources. In the maize endosperm, SSI and SSIII constitute the major apparent soluble SS activities [128], whereas in maize leaves no SSI transcript was detected [129]. In contrast, SSII and SSIII are the major apparent soluble SS in the pea seed and potato tuber [130-132], while transcripts of potato SSI were almost exclusively detected in leaves [133]. In Arabidopsis leaves, SSI is the major soluble SS, as judged by remaining SS activity of single ss mutants, followed by SSIII and SSII [116, 134]. Although expressed to a reasonable level, SSIV appears to contribute only little to total SS activity [116, 135]. It is important to note, however, that estimates of the apparent contribution of an SS may be biased; suppression of SSIII, for example, is often accompanied by an upregulation of SSI and/or GBSS, meaning that the comparison of total synthase activities in the presence or absence of SSIII not only reflect the contribution of SSIII. Furthermore, SS assays themselves may preferentially measure one class over another, leading to erroneous estimations of their relative activities.
Starch synthase I (SSI)

Loss of SSI activity causes distinct alterations in the CLD of amylopectin, particularly concerning the $\mathrm{A}-$ and $\mathrm{B}_{1^{-}}$chains that make up the clusters. Amylopectin from the endosperms of $s s I$ mutants from rice (in a japonica variety, i.e., rice with inactive SSIIa and a leaky mutation in GBSS [136]) and suppressor lines in wheat [137] has more short chains of DP 6 and 7, fewer chains of DP 8-12 and more chains of around DP 18. Similar changes have also been observed in leaf starch from Arabidopsis ssI mutants [122, 138]. It is striking that the chains that are depleted in the mutants have the same lengths as those that are preferentially synthesized by SSI in vitro. SSI from maize, kidney bean and rice were shown to favor short chains (usually DP $<10)$ as substrates [136, 139, 140] and SSI from Arabidopsis was more active on glycogen than on amylopectin [138]. These findings suggest that SSI elongates the short glucan chains derived from BE action (which are mostly DP 6) by a few glucan units (to a DP of around 8-10). These chains are then probably further elongated by SSII and possibly other SSs. However, since the majority of chains from BE action are still elongated in ssI mutants, the other SSs appear to be only partly dependent on SSI action.

It is interesting that the chains elongated in the absence of SSI appear to be elongated further, increasing the proportion of chains around DP 18 at the expense of shorter chains. Using modified glycogen substrates, it was reported that the activity of an N-terminally truncated maize SSI drastically decreases with external chain length, while its substrate binding strongly increases [139]. The authors suggested a scenario where these characteristics would make SSI stick to elongated glucan chains as an inactive enzyme, thus preventing the elongation by other synthases. Indeed, entrapment of SSI within the granule is to some extent commonly observed [128, 136, 140, 141]. Whether the extent of granule binding of SSI is really sufficient to block a significant fraction of its short chain products is unclear. Furthermore, other evidence has suggested that the granule localization of SSI is dependent on the starch binding of its interaction partner, SSII (see below).

More recent in vitro data showed that recombinant Arabidopsis SSI can actually synthesize chains up to DP 15 when incubated with maltoheptaose as primer [142] and, when assisted by a $\mathrm{BE}$, was able to produce a whole spectrum of chain lengths normally present within one crystalline layer of amylopectin (i.e., $\mathrm{A}$ and $\mathrm{B}_{1}$ chains [143]). An N-terminally truncated version of barley SSI even produced chains DP $>40$ when maltohexose was used as primer [144]. Thus, the real reason why some of the short chains generated by SSI are not extended further in wild-type conditions remains unclear. 
Arabidopsis SSI is redox-sensitive and requires reducing conditions for activity [145]. According to the crystal structure of barley SSI, it was proposed that a disulfide bridge between cysteines 126 and 506 can be formed, blocking the active site [65]. However, single mutation of each of these cysteine residues did not render SSI completely redox-insensitive, and the C506S mutant protein lost most of its activity.

\section{Starch synthase II (SSII)}

The effects of SSII deficiency have been characterized in potato tubers [133, 146-148], pea seeds [149], the endosperms of wheat [150], barley [151], rice (i.e., a japonica rice variety [152, 153]) and maize [154] and in Arabidopsis leaves $[119,122,134]$. The observed phenotypes are remarkably similar and include a distinct change in amylopectin fine structure: there is an increased abundance of chains around DP 8 and decreased abundance of those around DP 18, i.e., a shift toward shorter chain lengths. In addition, ssII mutant starches often have more amylose, altered granule morphology and reduced starch crystallinity. In Arabidopsis, small amounts of soluble glucan were also reported to accumulate alongside the starch [122].

Based on the alterations in CLD, it appears that SSII elongates chains of around DP 8 (the chains elongated by SSI) to lengths around DP 18. This direct interpretation is complicated by the fact that, at least in cereals, SSII interacts with SSI and class II BEs (see section "The role of complex formation and phosphorylation of starchbiosynthetic enzymes"). Hence the loss of SSII may have pleiotropic effects on these enzymes, making it difficult to assess how much of the phenotype is directly due to the absence of SSII activity. For instance, the modest increase in amylose in ssII mutants might be caused by altered BEII activity (see section "Specificities of BE classes"). However, it is likely that the changes in amylopectin fine structure are caused by the lack of SSII activity. First, when a recombinant rice SSII was incubated with amylopectin from a rice ssII mutant, it specifically elongated the aberrantly short chains so that the modified glucan now appeared more wild-type like [155]. Second, the loss of SSI activity in an ssII mutant background caused ssI-typical alterations, indicating that SSI was still active [122, 134, 136]. Third, the changes in amylopectin CLD are similar in dicots plants where there is no evidence for the formation of SSII-containing complexes.

\section{Starch synthase III (SSIII)}

Compared with SSI and SSII, the function of SSIII is less clear. Its suggested functions include the synthesis of long
B chains, the elongation of cluster-filling chains (partly redundant function with SSII) and the regulation of other starch-biosynthetic enzymes. Furthermore, SSIII is important for the initiation of starch granules, at least in the absence of SSIV. Consistent with the view of a versatile role, SSIII appears as a major soluble SS activity in all plants and tissues that have been analyzed to date. It also harbors the longest N-terminal extension among all SS, which carries starch-binding domains and predicted coiledcoil domains (Fig. 2).

Probably the best characterized function of SSIII lies in the synthesis of long, cluster-spanning $\mathrm{B}$ chains (i.e. $\mathrm{B}_{2}, \mathrm{~B}_{3}$ etc.). Fewer of these chains were observed in ssIII mutant starches from potato tubers [148], endosperms of maize [109, 156] and rice [157], and in C. reinhardtii [97]. Of the ssIII mutants characterized, only the Arabidopsis ssIII mutant [158] and the barley amol mutant do not display this phenotype (note that the amol mutation does not to abolish SSIII activity, however [159]).

Alterations in the short chain profile of amylopectin from ssIII mutants [147, 148, 157, 158, 160] indicate that SSIII is also involved in the synthesis of short A and B chains. These changes are subtle when compared to those caused by the lack SSI or SSII. In the absence of SSII, however, additional loss of SSIII significantly enhances the mutant phenotype in rice grains [80], potato tubers [147, 148] and Arabidopsis leaves [119], suggesting partially redundant functions between these two SSs. The ssII/ssIII double mutant of Arabidopsis produced tiny amounts of glucans with drastically shortened chains, a fraction of which was water soluble $[119,122]$. In potato tubers, the combined repression of SSII, SSIII and GBSS resulted in amylose-free starch with short-chained amylopectin, gels of which did not undergo retrogradation upon repeated freeze-thaw cycles-a preferred characteristic for the food industry [161].

Arabidopsis ssIII mutants were reported to have increased total soluble SS activity [158] and to produce more starch during the day $[117,158]$ in the leaf, leading to the suggestion that it has a negative regulatory function on other starch-biosynthetic enzymes. Other studies, however, reported slightly reduced soluble SS activity $[117,134]$ and starch levels [122, 134]. An increase in SSI and/or GBSS levels was observed in ssIII endosperms from maize [128] and rice [157] and in $C$. reinhardtii [97]. It is therefore possible that some of the alterations in amylopectin fine structure are caused by increased SSI levels. Furthermore, the observed increase in amylose content in ssIII endosperm starches from maize [156, 162] and rice [111, 157] may be due to enhanced GBSS activity. The increased action of GBSS is also likely to be the cause for other phenotypes associated with a deficiency in SSIII such as an increased number of extra-long amylopectin chains and 
fissured granules $[114,157]$; repression of GBSS in addition to SSIII in potato tubers suppressed these aspects of the ssIII phenotype [114].

\section{The initiation of starch granule formation: starch synthase IV (SSIV) and other factors}

To date, mutants with reduced SSIV activity were described only in rice [80, 163] and Arabidopsis [116-118]. Rice has two SSIV isoforms: OsSSIVa, which is expressed only little in leaves and endosperm, and OsSSIVb, which is generally higher expressed [79, 80]. Neither single repressors of $O s S S I V$ a or $O s S S I V b$ [80], nor null mutants of OsSSIVb (in a japonica variety; [163]) show marked alterations in starch content or structure in the seed endosperm. In contrast, null mutants of the single SSIV isoform in Arabidopsis show alterations in diurnal leaf starch content, having less starch at the end of the day and more at the end of the night compared with wild-type plants, despite having a normal amylopectin fine structure [116]. The Arabidopsis ssIV mutant also has remarkable alterations in the number and shape of starch granules: instead of around six discoid granules [164], chloroplasts from $s s I V$ mutants have zero, one or two granules, which are enlarged and spherical with a less electron-dense center $[116,118]$. In young $s s I V$ leaves, the chloroplasts were starch free [118]. Overexpression of AtSSIV in Arabidopsis increased total leaf starch content, although an increase in starch granule number was not reported [165].

Overall, Arabidopsis SSIV clearly has a unique function regarding the initiation and morphology of starch granules, and the degree of starch accumulation [116, 118]. Interestingly, the levels of ADPglucose (the substrate for SS) in $s s I V$ mutants are increased over 50 -fold suggesting that its consumption is strongly limited [118]. This is especially likely to be the case in starch-free chloroplasts where the remaining SS isoforms lack glucan substrate. In contrast, Arabidopsis plants having SSIV as sole soluble SS (i.e. ssI/ ssII/ssIII mutants) produce similar numbers of granules per chloroplast as the wild type, despite having only little, aberrant starch overall [117]. It will be interesting to see whether there are similar impacts on leaf starch in the rice $s s I V b$ mutant and repressor lines.

Analyses of multiple SS mutants in Arabidopsis indicate that SSIII (but not SSI and SSII) is required to achieve some starch synthesis in the absence of SSIV: Arabidopsis ssIII/ssIV mutants almost completely fail to synthesize starch and display chlorosis and stunted growth [37, 117]. Despite a strongly reduced rate of photosynthesis, these mutants still accumulate around 100 times more ADPglucose, unbalancing the adenylate pool and possibly explaining the pleiotropic defects observed [37]. The consequence of losing SSIIIa and SSIVb in japonica rice was quite different, although still striking. The $s s I I I a / s s I V b$ double mutant was still able to produce substantial amounts of endosperm starch, but accumulated spherical and loose granules instead of the polyhedral compound-type starch granules normally observed [163]. This phenotype was accompanied by an uneven amyloplast surface and a modified galactolipid composition of membranes. Alterations in the latter have previously been implicated in the transition from simple- to compound-type granules in the opaque 5 maize mutant [166]. Toyosawa and colleagues hypothesized that SSIVb may be important for the structural integrity of as-yet uncharacterized, membranecontaining septum-like structures [163] that may form a mold within amyloplasts for casting starch into the polyhedral shape [167]. Possible reasons for the phenotypic differences between $s s I I I a / s s I V b$ rice and $s s I I I / s s I V$ Arabidopsis include the presence of other SSIII and SSIV isoforms in the rice endosperm and/or mechanistic differences in storage and transitory starch granule formation.

The function of SSIV and the mechanisms for determining granule number and shape remain enigmatic. Glycogen biosynthesis in other organisms begins with selfglucosylation either of glycogen synthases (in bacteria; [168]) or of specialized proteins named glycogenins (in eukaryotic cells; $[169,170])$. Introducing the self-priming A. tumefaciens glycogen synthase into Arabidopsis ssIII/ $s s I V$ double mutants indeed restored initiation of multiple starch granules per chloroplast, but the granules' morphology was still like those found in the ssIV [118]. Attempts to confirm such a self-priming activity in recombinant AtSSIV (and AtSSIII) were not successful [117], although AtSSIII was found to catalyze unprimed glucan formation in the presence of ADPglucose [117]. An autoglucosylation function may not be required to explain the initiation of starch polymers in photoautotrophic tissues if ideas about de novo synthesis of maltose during photosynthesis prove to be true [171, 172]: all four soluble SSs from Arabidopsis are able to elongate maltose and longer malto-oligosaccharides (but not glucose) [142].

Arabidopsis SSIV was reported to interact with two plastoglobule-associated proteins, the fibrillins FBN1a and FBN1b [75]. This interaction was dependent on the presence of the non-catalytic N-terminus of SSIV predicted to contain coiled-coil motifs (Fig. 2). Localization studies of SSIV report it to be a stromal protein loosely targeted to distinct spots within the chloroplast-initially proposed to be the edges of granules [117]. However, more recently, it was reported to be associated to thylakoid membranes [75]. In the rice endosperm, SSIVb also had a sub-plastidial localization, being predominantly distributed in the space between starch granules, although distinct spots were rarely observed [163]. Given its hypothesized role in determining granule number and morphology, the specific positioning 
of SSIV within the plastid may well turn out to be a factor of critical importance. In turn, understanding the factors that influence its localization-to the granule or to membranes-is likely to give completely new insight into the control of starch formation.

Additional factors have been implicated in the control of starch granule number. A number of proteins that selfglucosylate using UDPglucose were described over the years (e.g. [173-175]), yet none were reported to have plastidial targeting signals, but were mostly implicated in cell-wall biosynthesis [176]. Proteins homologous to glycogenins were reported in Arabidopsis, and suppression of one containing a predicted chloroplast-targeting signal appeared to reduce starch accumulation [177]. This observation, based on iodine staining, has not been substantiated. Interestingly, mutant phenotypes have also suggested the involvement of $\alpha$-glucan phosphorylase and isoamylase DBEs as influencing starch granule number (described in later sections). It is also interesting to note that one of the proteins implicated in the reversible glucan phosphorylation, Starch Excess4 (SEX4)—whose activity is required for starch degradation at night-also has a profound impact on starch granule morphology, as its loss resulted in very large, round granules [26]. This phenotype has not been reported for other mutants affected in starch degradation and its basis has yet to be investigated.

\section{Classes and domain structure of branching enzymes (BE)}

Starch-branching enzymes (E.C. 2.4.1.18) belong to the $\alpha$ amylase superfamily of enzymes (also termed glycoside hydrolase family 13; CAZy: [59]; recently reviewed [178]. They cleave an $\alpha$-1,4-glucan chain and transfer the cleaved portion to the C6 position of a glucose unit from the same or another chain, creating an $\alpha-1,6$ linked branch. In doing so, BEs generate additional substrates for the SSs (i.e., nonreducing ends of chains). BEs share a common three-domain structure: an N-terminal domain containing the CBM of family 48, a central catalytic $\alpha$-amylase domain characteristic for GH13 family members and a C-terminal domain present in several $\alpha$-amylases (Fig. 3).

According to sequence similarities, BEs are separated into class I (or family B) and class II (family A) enzymes. Class I enzymes generally occur as a single isoform in planta, with the exception of Arabidopsis, which does not contain a class I BE [179]. Class II is represented by a single gene in potato and pea, but two isoforms-BEIIa and BEIIb-occur in the cereals. These have distinct expression patterns: in maize, rice and barley, the expression of BEIIb is restricted to the grain, while BEIIa is found in all tissues but at often lower levels [180-183]. Arabidopsis also has two type II BEs (BE2 and BE3), both

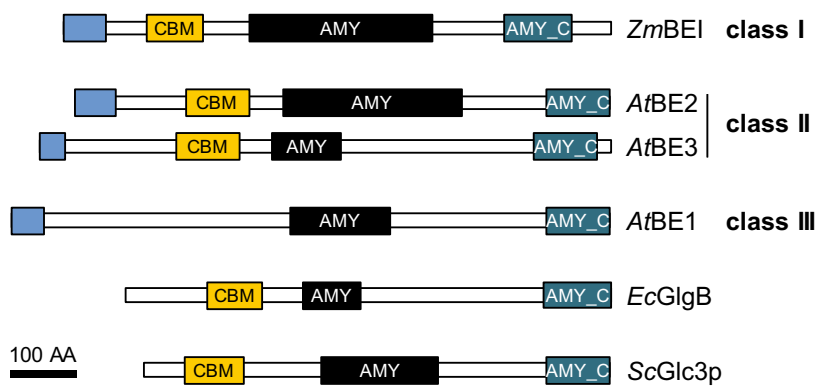

Fig. 3 The domain structure of branching enzymes (BE). BE classes can be distinguished by sequence but share a common domain structure. Depicted are plastidial transit peptides (N-terminal blue boxes), carbohydrate-binding modules of family 48 (orange boxes, CBM), catalytic $\alpha$-amylase family domains (black boxes, AMY) and the all- $\beta$ domains typically found in the $C$ terminus of $\alpha$-amylases family members (blue boxes, AMY_C). Domain predictions were obtained as described in Fig. 2. No coiled-coil domains were predicted with the settings described in Fig. 2. The domain structure is conserved between classes and orthologs, although the length of the predicted catalytic $\alpha$-amylase family domain varied. As Arabidopsis does not have a class I BE, maize BEI $(\mathrm{ZmBEI})$ is included for comparison, as are glycogen BEs from budding yeast ( $\mathrm{Sc} \mathrm{Glc} 3 \mathrm{p}$ ) and E. coli $(E c \mathrm{GlgB})$. AtBE1 is a putative BE of class III which lacks the CBM48 and has not yet been shown to display branching activity. Bar 100 amino acids (AA)

of which are expressed in leaves and appear largely functionally redundant [179].

Protein-sequence homology revealed a putative third class of BE. Genes belonging to this class III were found in Arabidopsis (BE1; [179]), rice, poplar and maize (BEIII; [78, 184]. Despite the high homology within this class (around $60 \%$ ), the proteins share only around $30 \%$ identity with BEs from class I and II [184]. To date, functional analysis on this putative BE was only done in Arabidopsis, where knock-out mutants were first reported have a wild-type phenotype [179], then to be inviable [185]. Branching activity was not reported by either group. Further work is required to reveal the catalytic activity and biological function of these proteins.

\section{Specificities of branching enzyme (BE) classes}

The specific placement of branches by BEs is believed to be a major determinant of the cluster structure of starch (i.e., the enrichment of branches in certain, regularly spaced regions). However, due to our limitations in assessing the actual distribution of branch points, investigations on the specificity of BE isoforms often focused more on the lengths of transferred chains rather than their placement, primarily by comparing the CLDs of glucans before and after the in vitro modification by a BE. Accordingly, class I BEs tend to transfer slightly longer chains than BEII and are more active towards amylose, whereas class II BEs typically prefer amylopectin [186- 
190]. Further, BEI from rice modified a phosphorylaselimit amylopectin, suggesting that this BE has can transfer already-branched chains [190, 191]. Obtaining the phosphorylase-limit CLDs after BE action allows modifications on the inner branching structures to also be analyzed [191]. This revealed that all rice BEs produce a relatively broad distribution of distances between new and old branches [191]. In contrast, the glycogen BE from E. coli (EcGlgB), while transferring chains of similar length to plant BEIIs, differed in that it preferentially placed new branches only three glucose units away from an existing branch point [191]. This structural trait was also observed when $E c \mathrm{GlgB}$ was expressed in an Arabidopsis line deficient in its endogenous BEs (be2/be3 double mutants) [192]. Nevertheless, $E c \mathrm{GlgB}$ restored the synthesis of insoluble glucans [192, 193], albeit in reduced amounts and in the form of irregular particles.

Mutants of BEI have been analyzed in maize [194, 195], rice [6, 196] and wheat [197] endosperms, and the gene repressed in potato tubers [198]. In all cases, deletion or reduction of BEI resulted in only minor changes on starch structure/amount at best, such that its function in vivo remains unclear. Reduction of most or all BEII activity, however, caused marked alterations in starch and the well-known amylose-extender (ae) phenotype. This phenotype was observed in beIIb mutants of maize [199] and rice [200], in beIIa mutants of durum wheat [201], in mutants of BEII in pea (yielding the wrinkled-seed mutants studied by Gregor Mendel [202, 203]) and in double repressor lines of BEIIa and BEIIb in wheat and barley [204, 205]. The ae phenotype is characterized by altered amylopectin structure with longer external and internal chains and, in some cases, increased levels of amylose [6, 106, 202, 206-208]. Due to its special swelling and gelatinization properties and reduced digestibility in the digestive tract, ae starch is of special interest both for industry and human health $[11,30]$. In rice grains, expression levels of BEIIb correlated with amylopectin structure, and increasing repression of BEIIb was accompanied by a change from $\mathrm{A}$ to $\mathrm{C}$ to $\mathrm{B}$ polymorph [207, 209]. Upon overexpression of BEIIb, glucans with lower crystallinity than normal were observed and soluble glucans also accumulated [209].

In potato tubers, repression of BEII led to amylopectin with longer chains [210], but a high amylose content was only seen upon suppression of both class I and II BE genes [211]. This high-amylose starch also had high phosphate levels - another feature of considerable industrial interest. However, the overall starch yield was severely reduced [211]. Overexpression of BEII in potato was recently reported to increase the abundance of short amylopectin chains (mostly DP 6), lower the gelatinization temperature of the starch and to reduce the phosphate content [212].
Some mutations in BE affect leaf starch metabolism. Maize beIIa mutants have normal endosperm starch, but mostly replace leaf starch by a glucan of low molecular weight and a low degree of branching [213, 214]. Although BEIIa is the predominant BE in maize leaves, transcripts of BEI were also found in the leaf [214], presumably accounting for the residual glucan synthesis. In Arabidopsis, mutants disrupted in both class II BEs (BE2 and BE3) exhibit a complete loss of $\mathrm{BE}$ activity and fail to produce starch. Instead they accumulate high amounts of maltose [179]. It was hypothesized that this water-soluble glucan was generated during the simultaneous synthesis of linear chains by SSs and degradation by the plastidial $\alpha$-amylase 3 (AMY3) and/or $\beta$-amylases.

Collectively, the numerous studies of BEs show that, as expected, branching activity is absolutely required for amylopectin synthesis. They also show that BE specificities differ and that they significantly influence the final glucan structure. Furthermore, their activity relative to that of SSs is important, which is illustrated by the change in glucan structure when expressed to differing extents [209, 212]. Nevertheless, BEs are not the sole determinants for the synthesis of crystallization-competent glucans, as demonstrated by the ability of $E$. coli glycogen BE to restore some insoluble glucan synthesis [192, 193]. It should also be kept in mind that BEs form complexes with other starchbiosynthetic enzymes, which might influence their functions (described below).

\section{Debranching enzymes (DBEs) and the trimming of glucans}

Plant DBEs hydrolyze $\alpha$-1,6-linkages and release linear chains. They belong to the glycoside hydrolase family 13 (CAZy: [59]) and share the central $\alpha$-amylase domain and a starch-binding domain with BEs (Figs. 3, 4). They can be further divided into two types: isoamylases (ISAs; E.C. 3.2.1.68) and limit-dextrinase (LDA; E.C. 3.2.1.41). The two types can be distinguished by protein sequences and substrate specificity, as only LDAs can efficiently degrade pullulan $[215,216]$, a yeast-derived glucan consisting of $\alpha$ 1,6-linked maltotriosyl units (hence the enzyme's alternative name pullulanase or PU1). Plant genomes encode three classes of isoamylase-ISA1, ISA2 and ISA3-and one LDA.

ISA1 and ISA2 are involved in debranching during the synthesis of amylopectin and are thus in the focus here. They act together as a heteromultimeric enzyme, and ISA1 additionally forms active homomultimers in some species (described below) - hereafter we use "ISA" to refer to both homomeric and heteromeric activities. In contrast, ISA3 and LDA primarily debranch starch during its degradation and mutants of these enzymes often have starch-excess 


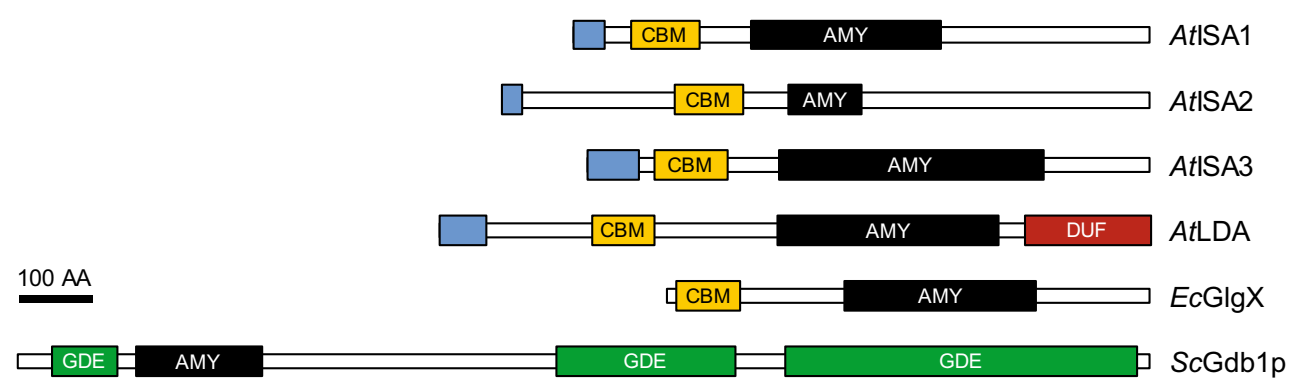

Fig. 4 The domain structure of debranching enzymes. The Arabidopsis debranching enzymes (AtISA1, AtISA2, AtISA3, AtLDA) and $E$. coli debranching enzyme $(E c \mathrm{GlgX})$ share the domain structure with BEs. The indirect debranching enzyme from budding yeast ( $S c$ Gdb1p) is shown for comparison. Depicted are the plastidial transit peptides (N-terminal blue boxes), carbohydrate-binding modules of family 48 (orange boxes, CBM), catalytic $\alpha$-amylase family domains (black boxes, AMY) and a Pfam domain of unknown function, DUF3372 (red box, DUF). Domain predictions were obtained as described in Fig. 2. No coiled-coil domains were predicted with the

(sex) phenotypes [217-220]. Nevertheless, ISA3 and LDA do influence the glucan made in the absence of ISA, although they cannot replace its specific function [121, 218, 221-223].

Mutants lacking ISA partly replace starch by a watersoluble polysaccharide in the endosperms of maize [224, 225], rice [226] and barley [227], in potato tubers [228], Arabidopsis leaves [120, 218] and in C. reinhardtii [229]. In terms of branching level, wavelength of maximum absorption after complexion with iodine and molecular weight, this water-soluble glucan appears reminiscent of glycogen and was hence called phytoglycogen [230]. In most cases, insoluble starch, albeit with small structural alterations, is still made. Only in $C$. reinhardtii and in japonica rice (i.e., rice with an ssII background), do isal mutants completely fail to produce starch [226, 229]; in the latter, this is dependent on the mutated ssII allele [231].

A common model to explain the accumulation of phytoglycogen is the "trimming" model [232]. According to this model, ISA removes excess branches from a newly created amorphous zone in "pre-amylopectin" so that only the appropriate chains are elongated by SSs. In the absence of ISA, the high number of branches would result in steric limitations, abolishing regular structures and the synthesis of further lamellae. Consistent with this, Arabidopsis phytoglycogen is indeed enriched in branches separated by short distances [120]. However, while this model regards debranching by ISA as a mandatory step, careful observation of mutants lacking the enzyme suggest that this is not strictly essential for making a crystallization-competent glucan: Not only do most ISA-deficient mutants make some starch, often both starch and phytoglycogen are made within the same plastid and some cell types/tissues appear little affected (e.g. bundle-sheath cells from Arabidopsis settings described in Fig. 2. Where full-length sequences could be obtained, the domain structures of classes were conserved among orthologs in various species. $S c$ Gdb1p contains three Pfam glycogendebranching enzyme (GDE) domains (hGDE_N, hGDE_central and GDE_C, from $\mathrm{N}$ to $\mathrm{C}$ terminus). These are characteristic for eukaryotic GDEs, which combine oligo- $\alpha-1,4 \rightarrow \alpha-1,4$-glucanotransferase (EC 2.4.1.25) and $\alpha$-1,6-glucosidase (EC 3.2.1.33) within a single enzyme and debranch glycogen in a two-step mechanism. Bar 100 amino acids (AA)

and maize leaves [120, 233, 234]). Streb et al. showed that Arabidopsis leaf starch is completely replaced by phytoglycogen in the isal/isa2/isa3/lda mutant lacking all DBEs [121]. This suggested some functional overlap between the DBEs-a result consistent with previous observations in Arabidopsis [218, 223], maize [217] and rice [221, 222]. However, the additional mutation of the starch degrading enzymes $\alpha$-amylase 3 (AMY3) in the debranching mutant background partly restored starch granule synthesis, showing that debranching, while part of the biosynthetic process, is not an absolute requirement [121]. This result was in-line with the earlier observation that phytoglycogen is prone to degrading enzymes [120], and suggested that the modifications made by degradative enzymes also served to prevent nascent molecules from forming insoluble starch granules. Recently, genetic analyses in Arabidopsis [122] and rice [231] suggested that the lengths of the cluster-filling chains also influence whether insoluble glucans are made in the absence of ISA; relative increases in longer chains promoted insoluble glucan formation, while enrichment of shorter chains abolished them altogether. For instance, ssI/isa double mutants have longer $\mathrm{A}$ and $\mathrm{B}_{1}$ chains and produce significantly more starch than isa single mutants [122] (Fig. 5). It thus seems that debranching facilitates or accelerates the crystallization of glucans rather than formally enabling it. The crystallization itself in solid granules may in turn protect the glucans from premature degradation by amylases [120, 121].

Interestingly, recent studies suggest that ISA itself can act in a degradative fashion under some circumstances. First, expression of AtISA1-AtISA2 in E. coli [235] and S. cerevisiae (B.P. and S.C.Z., unpublished data) impeded the accumulation of glycogen instead of yielding a more amylopectin-like glucan. Second, far fewer glucans were 
Fig. 5 Modulation of the isa mutant phenotype by starch synthases. Transmission electron micrographs of Arabidopsis chloroplasts at the end of day. Wild-type plants (WT) contain starch granules (black arrowheads) in the mesophyll and epidermis. The isal/isa2 mutant accumulates predominantly phytoglycogen (white arrowheads) in the mesophyll, but still makes starch in the epidermal cells. Additional loss of SSI restores the formation of starch granules in the mesophyll, most likely due to a relative increase in the proportion of longer, clusterfilling chains that promote crystallization, despite aberrant branching. In contrast, additional loss of SSII completely abolishes the synthesis of insoluble glucans, even in the epidermal cells. This probably stems from the relative increase in shorter chains in the absence of SSII, impairing the formation of secondary and tertiary structures. Epi epidermal cell, Pal palisade cell, Bars $1 \mu \mathrm{m}$. Adapted from [122], Copyright American Society of Plant Biologists (http://www.plantphysiol.org)
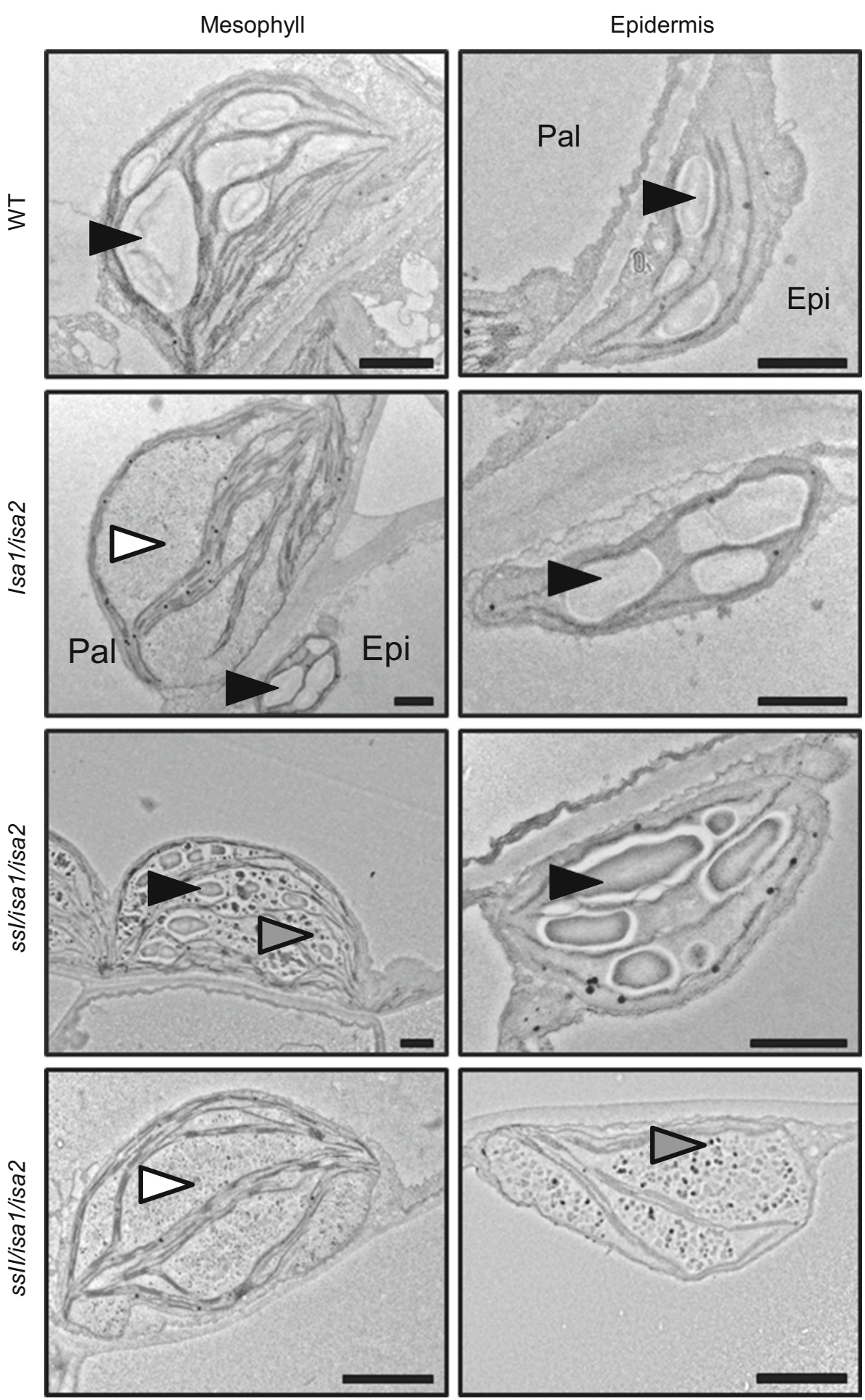

observed in the Arabidopsis ssII/ssIII double mutant compared with the ssII/ssIII/isa triple mutant [122]. Notably, the glucans made in ssII/ssIII plants showed structural similarities to glycogen in that they had much shorter chains than wild-type amylopectin and were partly found in the water-soluble fraction [122]. These data indicate that debranching by ISA to promote crystallization requires the appropriate glucan substrate-a pre-amylopectin with adequate chain lengths and/or branching pattern. If the glucan structure is incompatible with (rapid) crystallization 
upon debranching (e.g. because of insufficiently long chains), the ongoing accessibility may cause excess debranching and ultimately glucan degradation.

A purely degradative action of ISA may also provide an explanation for the formation of numerous small granules/particles in isa mutants $[227,228,236]$. In Arabidopsis, this phenotype has been suggested to be a secondary effect resulting from the enhanced $\alpha$ - and $\beta$ amylolytic degradation of soluble glucans: this could yield small soluble oligosaccharides that could serve as primers for glucan synthesis or as nucleation sites for starch granules [121]. However, small branched oligosaccharides, possibly representing the earliest stage of normal glucan synthesis, would also be excellent targets for debranching by ISA, as mentioned above. Debranching and clearance of such glucans could then limit the pool of potential nucleation sites for starch granules.

\section{Distinct functions of isoamylase homo- and heteromultimers}

Depending on the species, ISA1 either acts exclusively in heteromultimeric complexes formed between ISA1 and ISA2, or both as heteromeric and homomeric complexes. The Arabidopsis isal, isa2 and isal/isa2 mutants show identical phenotypes [120]. Moreover, AtISA1 and AtISA2 have a high native molecular mass, interact with each other and are stable only in the presence of their partner [120, 235]. Catalytic activity was only observed when both AtISA1 and AtISA2 were present [235, 237]. These data strongly suggest that ISA1 and ISA2 form an obligate heteromultimeric enzyme. ISA2 carries substitutions in amino acid residues important for catalysis, probably rendering it non-catalytic. ISA1 is therefore likely to be the catalytic subunit, with ISA2 being required for the enzyme's stability, and possibly for its specificity and/or regulatory properties [235, 238, 239]. Similarly, in potato, only a heteromultimeric complex of ISA1 and ISA2 was found [240], although potato ISA1 was active on its own when recombinantly expressed as an S-tagged protein in E. coli [238].

In other species it is clear that ISA1 also acts as a homomultimer. One or several homomeric complexes of ISA1 were found in addition to at least one ISA1/ISA2 complex in rice and maize grains and in $C$. reinhardtii [240-242]. In a recent crystal structure, C. reinhardtii ISA1 had an elongated structure and paired with another ISA1 in a tail-to-tail fashion, although the existence of higher multimers could not be excluded [242]. Maize and rice isa 2 mutants, which have only the ISA1 homomer, had similar endosperm starch synthesis as wild-type plants, suggesting that the ISA1 homomers are sufficient [241, 243]. However, in an ssIII mutant background, loss of ISA2 resulted in the accumulation of phytoglycogen in maize kernels [160] —an intriguing, albeit unexplained observation. The ISA1/ISA2 heteromultimer was also reported to be more thermostable and have a higher affinity for phytoglycogen than ISA1 alone [240]. Thus, both the catalytic properties and stability of ISA1 seem to be influenced by ISA2, and both homomeric and heteromeric ISAs may be required for optimal amylopectin synthesis, at least in some conditions.

\section{The role of complex formation and phosphorylation of starch-biosynthetic enzymes}

For the past decade there has been mounting evidence for the formation of complexes between starch-biosynthetic enzymes and for the phosphorylation of these enzymes. Recently, two additional complexes were identified which are distinct as they involve proteins without apparent catalytic functions (see section "Starch-binding proteins and other novel proteins"). In an early study investigating this topic, co-immunoprecipitation indicated that BEIIb interacts with BEI and with starch phosphorylase in the wheat endosperm [123]. Treating the protein extract with alkaline phosphatase abolished these interactions, while incubation with ATP had the opposite effect. Thus, phosphorylation was proposed to be a prerequisite for complex formation, consistent with the observation that all wheat BEs can be phosphorylated [123]. Later, size-exclusion chromatography (SEC) of maize endosperm amyloplast extracts showed that SSII, SSIII, BEIIa, BEIIb occur to varying extents as non-monomeric forms. Pair-wise interaction tests via immunoprecipitation, affinity purification and yeast twohybrid suggested a phosphorylation-dependent complex of SSIII, SSII, BEIIa, BEIIb (and possibly SSI) and a second, similar complex without SSIII [73, 74]. Meanwhile, Tetlow and coworkers reported other phosphorylation-dependent complexes in the wheat endosperm, among them one between SSI, SSII and BEIIa or BEIIb [124]. This observation was also based on pair-wise coimmunoprecipitation, similar elution profiles obtained using SEC, and subsequent western-blotting of cross-linked fractions.

The association of SSI, SSII and a class II BE appears to be conserved at least within the cereal endosperm, as evidence for it was also found in maize [125], barley [126] and in rice [127]. In wheat and barley seeds, where BEIIa and BEIIb have redundant functions, this complex contains either of them and, in barley, possibly both [124, 126]. In the endosperm of maize and rice, where BEIIb is the dominant BE, BEIIa normally is not associated with the complex [125, 127].

Knowing about the existence of these protein complexes inevitably raises the question of their significance. In 
particular, it is important to understand how the functions of enzymes in complex differ when compared to those of their monomeric forms. This information will strongly affect the interpretation of mutant phenotypes and therefore our understanding of the role of individual enzymes: if the lack of a single enzyme abolished the formation of a whole complex and altered the activities of the remaining now solely monomeric or partially complexed enzymes, the resulting phenotype would not only result from the missing enzyme activity but also from the alteration of the biosynthetic machinery as a whole.

In ssII mutants, SSI and the interacting BEII(s) consistently appear less in the granule-bound fraction [150, 151, 244]. This was also observed in a starch-binding mutant of SSII [245]. Furthermore, in the absence of BEIIb in maize, a modified complex is formed in the endosperm: SSI and SSII now interacted with BEI, BEIIa and phosphorylase instead [125, 246]. Similarly, repressed BEIIa or BEIIb was replaced by BEI and phosphorylase in the complex in barley [126]. In both cases, protein replacement was reflected in the profile of granule-bound proteins: the newly complexed enzymes became granule bound, together with their complex partners and GBSS [125, 126]. This suggests that proteins in the complex have a higher affinity for starch. Nevertheless, it is worth noting that both BEIIb and SSI can bind starch on their own [139, 245, 246] and it remains unclear whether a tight association or even entrapment is required for optimal activity.

A potential biological function for complex formation could be to channel substrates from one enzyme to another-a newly created branch resulting from BE action could be directly elongated first by SSI and then by SSII, thereby increasing the overall efficiency of the process. It is also possible that the complex confers enzymatic specificity; for instance, steric limitations of the whole complex could define the length of a chain that is transferred by a BE or where exactly a new branch is placed. Tetlow and Emes [115] further suggested that complex formation could regulate enzyme activity allosterically and/or could protect a growing glucan from degrading enzymes. Still, none of these hypotheses has yet been tested.

Similarly, the role of phosphorylation of BEs and some SSs [28] remains enigmatic. Besides promoting complex formation, phosphorylation also increased the activity of stromal BEIIa and BEIIb in wheat [123]. Mutating conserved phosphorylation sites of maize BEIIb to serine drastically reduced the activity of the recombinant protein in vitro [247]. Since this activation happened in the absence of its interaction partners, it shows that phosphorylation does not necessarily increase BEIIb activity through complex formation. The authors furthermore presented evidence for the involvement of $\mathrm{Ca}^{2+}$-dependent protein kinases in phosphorylation of BEIIb.
It is clear that there will be much need for detailed biochemical and structural analyses of these protein complexes in the future. Particularly the creation of mutant proteins that are still active, but unable to interact with its enzymatic partners, would help in establishing the importance of the complexes.

\section{Additional factors with putative implications in starch synthesis}

\section{The reversible phosphorylation of glucans}

The reversible phosphorylation of starch is best characterized in Arabidopsis where it is pivotal for efficient degradation. It is believed that phosphorylation of glucosyl units at the $\mathrm{C} 6$ or $\mathrm{C} 3$ positions (exerted by glucan, water dikinase, GWD, or phosphoglucan, water dikinase, PWD, respectively [248, 249]) disrupts and destabilizes the helical structures formed by glucan chains, rendering them accessible to degrading enzymes, in particular $\beta$-amylases [250]. Since exo-acting $\beta$-amylases cannot degrade past phosphate groups, these need to be hydrolyzed concomitantly by the phosphoglucan phosphatases SEX4 (hydrolyzing at C6 and C3 [251]) and Like-SEX4 2 (LSF2; hydrolyzing at C3 [252], recently reviewed in [253]).

However, glucan phosphorylation is not confined to the dark period. Arabidopsis leaf starch made during a single photoperiod is C6- and C3-phosphorylated, showing that both GWD and PWD are active during the day. Furthermore, lsf2 mutants have increased levels of C3 phosphorylation at the end of the day, even though these mutants almost completely degrade their starch at night. This suggests that phosphate groups introduced during the day are normally also being removed by LSF2 [252]. In addition, it has been shown that the amount of C6-bound phosphate in Arabidopsis starch at the end of the day is variable and correlates positively with photoperiod [254]. Incubating potato tuber disks with glucose and radiolabeled orthophosphate resulted in radiolabeled phosphate in starch, also indicating that phosphate is incorporated during net synthesis of storage starch [255].

The relevance of phosphorylation during synthesis is not clear yet. Starches from Arabidopsis gwd mutants, which are essentially phosphate free, have a normal internal structure but differ in their granular surface, which is irregular and displays shorter chains [256]. These differences may, however, be secondary effects from incomplete starch degradation during the night and the subsequent synthesis of glucans on top of these altered granular surfaces. Arabidopsis gwd mutants also have only little net starch synthesis during the day. This could mean that lack of GWD inhibits starch synthesis generally [257]. However, by silencing GWD during an extended night, 
Skeffington and colleagues obtained plants without remaining starch and GWD, and these synthesized wildtype amounts of starch in the following day [257]. It, thus, appears unlikely that GWD is directly required during the process of starch synthesis. Rather, phosphorylation of glucans by GWD for efficient glucan degradation during the night may be important subsequent starch synthesis: either directly by providing proper starting material or indirectly by affecting carbon partitioning ( $g w d$ mutants starve during the night, which can influence the utilization of photoassimilates the following day).

\section{$\alpha$-Glucan phosphorylase-phosphorolysis or synthesis?}

$\alpha$-Glucan phosphorylase (EC 2.4.1.1) catalyzes the reversible reaction $(\alpha-1,4-\text { linked glucose })_{n}+$ glucose-1phosphate $\longleftrightarrow(\alpha \text {-1,4-linked glucose })_{n+1}+$ orthophosphate. Higher plants have two classes of phosphorylase: a plastidial and a cytosolic one. The plastidial class, named Pho1, PhoL (because of its low affinity towards glycogen) or PHS1, carries a 78-amino acid insertion near the glucan-binding site and shows highest affinity towards linear glucans, especially malto-oligosaccharides. By contrast, the cytosolic class, named Pho2, $\mathrm{PhoH}$ or PHS2, prefers branched substrates such as glycogen [258, 259].

The function of Pho1 is ambiguous, to the extent that it is not even clear whether it acts in a synthetic or phosphorolytic (i.e., degrading) way in vivo. The plastidial concentration of orthophosphate typically exceeds that of glucose-1-phosphate manifold [260], which would favor phosphorolysis in vivo. Nevertheless, rice Pho1 was shown to catalyze chain elongation as well as chain shortening under comparable concentrations in vitro [261, 262]. Rice mutants of Phol produce endosperm starch with slightly shorter chains, lower gelatinization temperature and altered granule shape, although this phenotype was not fully penetrant [261]. An additional phenotype was observed with the majority of the grains being shriveled and containing little starch when plants were grown at lower temperatures $\left(20{ }^{\circ} \mathrm{C}\right)$ [261]. It was suggested that, under these conditions, Pho1 may work in a biosynthetic direction helping to initiate starch synthesis by synthesizing malto-oligosaccharide primers for SSs, explaining the conditional loss of starch in the mutants. However, repression of Pho1 in barley [263] had no apparent effect on starch granule initiation, although granule number was not assessed.

Nevertheless, the gene expression and/or enzyme activity of Pho1 correlates with that from known starchbiosynthetic genes in potato tubers [264] and the endosperms of maize, wheat and barley [263, 265, 266], consistent with a role in biosynthesis. If acting in the phosphorolytic direction, Phol could help degrade malto- oligosaccharides created during the glucan trimming by isoamylase, yielding glucose-1-phosphate for subsequent re-conversion to ADPglucose [267]. Given that Phol was found to interact with BEIIb and BEI in wild-type wheat and maize amyloplasts $[123,268]$ and with SSI, SSIIa and BEI in beII mutants of maize and barley [125, 126], Pho1 may also act indirectly by modifying their enzyme activities or directly on their products.

In $C$. reinhardtii-which differs from vascular plants in having two plastidial isoforms, PhoA and PhoB-loss of PhoB resulted in reduced starch content. The remaining starch furthermore had a higher relative amylose content and structural modifications [267]. Still, this phenotype was confined to conditions of nitrogen starvation where flux into starch is highest. PhoB also is more similar to the cytosolic than the plastidial class of vascular plants as it lacks the typical sequence insertion and has a low affinity for malto-oligosaccharides [267].

There has also been speculation that PhoI may be involved in starch degradation. However, no significant influence on leaf starch content was noted upon repression of the leaf isoform of Phol in potato [269] or in the phol mutant of Arabidopsis [270-272]. Although these reports point against an essential role during degradation of transitory starch, local accumulation of starch was observed around leaf lesions, leading to the speculation about a specific role for phosphorylase in providing respiratory substrates during stress responses [270, 273]. More recently, genetic evidence for the participation of Arabidopsis Pho1 in starch degradation has been obtained from Phol deficiency in the background of $s s I V$ mutants and those impaired in maltose metabolism [271, 272].

\section{Starch-binding proteins and other novel proteins}

In recent years, several novel proteins have been identified that influence starch structure and/or amount. In some cases, the impact on starch may be an indirect one whereas in others, the proteins may be part of a hitherto undiscovered aspect of the starch-biosynthetic process. In either case, the analysis of the underlying mechanisms has the potential to provide new insights into facets of starch biosynthesis that go beyond the core enzyme machinery, such as the regulation of starch synthesis or the influence of the plastidial environment on granule formation and morphology.

Peng and colleagues described the rice Floury Endosperm6 (FLO6), a plastidial protein with a CBM48 and the capacity to bind starch [274]. Grains deficient in FLO6 deposit a variety of starch granules with changes in morphology and amylopectin structure [274]. Interestingly, FLO6 physically interacted with ISA1, which by itself displayed no binding to starch. It was speculated that FLO6 
confers starch binding to ISA1 and that the flo6 phenotype results from altered ISA1 function. This is an important hypothesis to test given the importance attributed to ISA in trimming nascent amylopectin to facilitate its crystallization.

Another CBM48-containing plastidial protein, Protein Targeting To Starch (PTST), has been described in Arabidopsis [95, 104]. In addition to its CBM, PTST contains predicted coiled-coil motifs. It was shown that PTST binds to GBSS through interaction via a coiled-coil motif on GBSS and that this interaction enabled GBSS to bind to starch granules: loss of PTST resulted in a loss of GBSS from the granule in vivo and loss of amylose synthesis [95]. In addition to the biotechnological relevance (both high and low amylose contents are coveted starch traits), FLO6 and PTST thus constitute exciting examples of non-enzymatic proteins that seem to play an important role in targeting or modulating the activities of starch-biosynthetic enzymes.

Another class of non-enzymatic proteins was very recently discovered in Arabidopsis. Designated Early Starvation1 (EST1), this plastidial starch-binding protein was identified because mutants lacking it display a premature depletion of transitory starch at night [275]. This appears to stem from an alteration in starch granule morphology, resulting in the inappropriate daytime starch degradation and accelerated, uncontrolled starch degradation at night. In contrast, plants overexpressing EST1 developed a starch-excess phenotype indicative of inhibited starch degradation. Although the protein's precise molecular function is not known, genetic evidence argues against a direct inhibition of degrading enzymes by EST1. It is proposed that EST1 may somehow help glucan molecules align correctly within the granular matrix-a process that has, until now, been regarded to be spontaneous. Interestingly, a homolog of EST1, Like EST1 (LEST), seems to fulfill an opposite role: while lest mutants had a wild-type phenotype, overexpression lead to a low-starch phenotype, similar to that of estl mutants [275].

Changes in starch granule morphology in cereal endosperms have also been linked to perturbations of other cellular processes including ER stress [276], failure in storage protein trafficking [277] and altered lipid composition of plastid membranes [166]. These observations highlight the dependency of starch granule formation on the overall efficiency of plastid and cellular functioning. Plastid-localized Substandard starch grain4 (SSG4) may also fall into this category. Mutants lacking this protein have enlarged starch grains and plastids, potentially arising from a dysfunction during plastid development [278, 279]. Recently, loss of another stromal protein, Floury Endosperm7 (FLO7), was reported to cause structural and morphological alterations in starch. This phenotype was confined to the periphery of rice seeds where also FLO7 is predominantly expressed, but the function of FLO7 remains unknown [280].

Finally, other studies have begun to uncover regulatory factors that appear to influence starch structure and/or content by controlling the expression of starch-biosynthetic genes. For example, the transcription factors OsbZIP58 and Rice Starch Regulator1 (RSR1) were shown to regulate the expression of a series of starch-biosynthetic genes in rice grains, thereby influencing starch structure and granule packing $[281,282]$. Similarly, Floury Endosperm2 (FLO2), a nuclear protein with a TPR motif, influences starch granule morphology and the expression of starch-biosynthetic genes, presumably by interacting with transcription factors [283].

This diverse set of newly identified proteins serves to illustrate that there is much still to understand about starch biosynthesis and the cellular context in which it occurs. It is worth noting that most of the proteins described above are evolutionarily conserved within higher plants, and cross-species analyses will be an essential aspect of further investigations.

\section{Conclusions}

Here, we have presented recent research findings in the context of established knowledge and ideas about starch synthesis. Ongoing genetic studies both in model and nonmodel species continue to raise evidence for enzymatic interdependencies, but also take us closer to understanding the requirements for the synthesis of a crystallizationcompetent glucan. This is well illustrated by studies of the ISA DBE: its contribution to promoting crystalline starch is highly dependent on the prior action of synthetic enzymes to produce suitable substrates for it, and some aberrant substrates are prone to degradation by ISA, while others are capable of crystallization in its absence. The assembly of enzymes into complexes, emerging as a common theme in cereal storage starch biosynthesis, and the participation of non-enzymatic protein factors add potential new layers of complexity to this already intricate process.

Arguably, one major stumbling block is the lack of a simple heterologous system for starch granule synthesis. We are working towards the production of such a system in the yeast Saccharomyces cerevisiae with the vision that this could allow us and others to disentangle starch biosynthesis from concomitant degradation and characterize in detail the functional interplay between starchbiosynthetic enzymes. The demonstration that starch can be made in a heterologous system would also show that we know which enzymatic set(s) are sufficient for starch 
biosynthesis and stimulate other complementary research. Together with empirical data from in vitro studies, it would represent an excellent starting point for the creation of mathematical models capable of simulating the starchbiosynthetic process. Furthermore, a heterologous system could serve as a valuable tool to aid the targeted modification of our starch crops, given that we are still not able to produce the variety of starches required by industry in planta.

Acknowledgments We gratefully acknowledge funding from The Swiss National Science Foundation (Grant Number 31003A_153144), from the ERA-CAPS program (Grant Number 31CP30_163503), and from ETH Zurich.

Open Access This article is distributed under the terms of the Creative Commons Attribution 4.0 International License (http:// creativecommons.org/licenses/by/4.0/), which permits unrestricted use, distribution, and reproduction in any medium, provided you give appropriate credit to the original author(s) and the source, provide a link to the Creative Commons license, and indicate if changes were made.

\section{References}

1. Ellis RP, Cochrane MP, Dale MFB, Dupus CM, Lynn A, Morrison IM, Prentice RDM, Swanston JS, Tiller SA (1998) Starch production and industrial use. J Sci Food Agric 77:289-311. doi:10.1002/(SICI)1097-0010(199807)77:3<289: AID-JSFA 38>3.0.CO;2-D

2. Blennow A, Bay-Smidt AM, Leonhardt P, Bandsholm O, Madsen MH (2003) Starch paste stickiness is a relevant native starch selection criterion for wet-end paper manufacturing. Starch/Stärke 55:381-389. doi:10.1002/star.200300169

3. Zhang Y, Rempel C, Liu Q (2014) Thermoplastic starch processing and characteristics-a review. Crit Rev Food Sci Nutr 54:1353-1370. doi:10.1080/10408398.2011.636156

4. Pal SK, Liput M, Piques M, Ishihara H, Obata T, Martins MCM, Sulpice R et al (2013) Diurnal changes of polysome loading track sucrose content in the rosette of wild-type Arabidopsis and the starchless pgm mutant. Plant Physiol 162:1246-1265. doi:10. 1104/pp.112.212258

5. Fujita N, Satoh R, Hayashi A, Kodama M, Itoh R, Aihara S, Nakamura Y (2011) Starch biosynthesis in rice endosperm requires the presence of either starch synthase I or IIIa. J Exp Bot 62:4819-4831. doi:10.1093/jxb/err125

6. Abe N, Asai H, Yago H, Oitome NF, Itoh R, Crofts N, Nakamura Y, Fujita N (2014) Relationships between starch synthase I and branching enzyme isozymes determined using double mutant rice lines. BMC Plant Biol 14:80. doi:10.1186/14712229-14-80

7. Lafiandra D, Riccardi G, Shewry PR (2014) Improving cereal grain carbohydrates for diet and health. J Cereal Sci 59:312-326. doi:10.1016/j.jcs.2014.01.001

8. Ceballos H, Sánchez T, Morante N, Fregene M, Dufour D, Smith AM, Denyer K, Pérez JC, Calle F, Mestres C (2007) Discovery of an amylose-free starch mutant in cassava (Manihot esculenta Crantz). J Agric Food Chem 55:7469-7476. doi:10. 1021/jf070633y
9. Wang K, Henry RJ, Gilbert RG (2014) Causal relations among starch biosynthesis, structure, and properties. Springer Sci Rev 2:15-33. doi:10.1007/s40362-014-0016-0

10. Tharanathan RN (2005) Starch—value addition by modification. Crit Rev Food Sci Nutr 45:371-384. doi:10.1080/10408390590 967702

11. Raigond P, Ezekiel R, Raigond B (2014) Resistant starch in food: a review. J Sci Food Agric 95:1968-1978. doi:10.1002/ jsfa.6966

12. Pérez S, Bertoft E (2010) The molecular structures of starch components and their contribution to the architecture of starch granules: a comprehensive review. Starch/Stärke 62:389-420. doi:10.1002/star.201000013

13. Manners DJ (1989) Recent developments in our understanding of amylopectin structure. Carbohydr Polym 11:87-112. doi:10. 1016/0144-8617(89)90018-0

14. French D (1972) Fine structure of starch and its relationship to the organisation of starch granules. J Jpn Soc Starch Sci 19:8-25

15. Nikuni Z (1978) Studies on starch granules. Starch/Stärke 30:105-111. doi:10.1002/star.19780300402

16. Hizukuri S (1986) Polymodal distribution of the chain lengths of amylopectins, and its significance. Carbohydr Res 147:342-347. doi:10.1016/S0008-6215(00)90643-8

17. Bertoft E (2004) On the nature of categories of chains in amylopectin and their connection to the super helix model. Carbohydr Polym 57:211-224. doi:10.1016/j.carbpol.2004.04. 015

18. Jenkins PJ, Cameron RE, Donald AM (1993) A universal feature in the structure of starch granules from different botanical sources. Starch/Stärke 45:417-420. doi:10.1002/star.1993045 1202

19. Kassenbeck P (1978) Beitrag zur Kenntnis der Verteilung von Amylose und Amylopektin in Stärkekörnern. Starch/Stärke 30:40-46. doi:10.1002/star.19780300203

20. Imberty A, Perez S (1988) A revisit to the three-dimensional structure of B-type starch. Biopolymers 27:1205-1221. doi:10. 1002/bip.360270803

21. Imberty A, Chanzy H, Pérez S, Buléon A, Tran V (1988) The double-helical nature of the crystalline part of A-starch. J Mol Biol 201:365-378. doi:10.1016/0022-2836(88)90144-1

22. Pilling E, Smith AM (2003) Growth ring formation in the starch granules of potato tubers. Plant Physiol 132:365-371. doi:10. 1104/pp.102.018044

23. Gallant DJ, Bouchet B, Baldwin PM (1997) Microscopy of starch: evidence of a new level of granule organization. Carbohydr Polym 32:177-191. doi:10.1016/S0144-8617(97) 00008-8

24. Oostergetel GT, van Bruggen EFJ (1993) The crystalline domains in potato starch granules are arranged in a helical fashion. Carbohydr Polym 21:7-12. doi:10.1016/0144-8617(93) 90110-P

25. Jane J-L, Kasemsuwan T, Leas S, Zobel H, Robyt JF (1994) Anthology of starch granule morphology by scanning electron microscopy. Starch/Stärke 46:121-129

26. Zeeman SC, Tiessen A, Pilling E, Kato KL, Donald AM, Smith AM (2002) Starch synthesis in Arabidopsis. Granule synthesis, composition, and structure. Plant Physiol 129:516-529. doi:10. 1104/pp.003756.ing

27. Buléon A, Cotte M, Putaux J-L, D’Hulst C, Susini J (2014) Tracking sulfur and phosphorus within single starch granules using synchrotron X-ray microfluorescence mapping. Biochim Biophys Acta 1840:113-119. doi:10.1016/j.bbagen.2013.08.029

28. Grimaud F, Rogniaux H, James MG, Myers AM, Planchot V (2008) Proteome and phosphoproteome analysis of starch granule-associated proteins from normal maize and mutants 
affected in starch biosynthesis. J Exp Bot 59:3395-3406. doi:10. 1093/jxb/ern198

29. Blennow A, Bay-Smidt AM, Olsen CE, Møller BL (2000) The distribution of covalently bound phosphate in the starch granule in relation to starch crystallinity. Int $\mathrm{J}$ Biol Macromol 27:211-218. doi:10.1016/S0141-8130(00)00121-5

30. Santelia D, Zeeman SC (2011) Progress in Arabidopsis starch research and potential biotechnological applications. Curr Opin Biotechnol 22:271-280. doi:10.1016/j.copbio.2010.11.014

31. Viola R, Nyvall P, Pedersen M (2001) The unique features of starch metabolism in red algae. Proc R Soc B Biol Sci 268:1417-1422. doi:10.1098/rspb.2001.1644

32. Dauvillée D, Deschamps P, Ral J-P, Plancke C, Putaux J-L, Devassine J, Durand-Terrasson A, Devin A, Ball SG (2009) Genetic dissection of floridean starch synthesis in the cytosol of the model dinoflagellate Crypthecodinium cohnii. Proc Natl Acad Sci 106:21126-21130. doi:10.1073/pnas.0907424106

33. Deschamps P, Haferkamp I, D'Hulst C, Neuhaus HE, Ball SG (2008) The relocation of starch metabolism to chloroplasts: when, why and how. Trends Plant Sci 13:574-582. doi:10.1016/ j.tplants.2008.08.009

34. Stitt M, Zeeman SC (2012) Starch turnover: pathways, regulation and role in growth. Curr Opin Plant Biol 15:1-11. doi:10. 1016/j.pbi.2012.03.016

35. Gross P, Rees T (1986) Alkaline inorganic pyrophosphatase and starch synthesis in amyloplasts. Planta 167:140-145. doi:10. 1007/BF00446381

36. George GM, van der Merwe MJ, Nunes-Nesi A, Bauer R, Fernie AR, Kossmann J, Lloyd JR (2010) Virus-induced gene silencing of plastidial soluble inorganic pyrophosphatase impairs essential leaf anabolic pathways and reduces drought stress tolerance in Nicotiana benthamiana. Plant Physiol 154:55-66. doi:10.1104/ pp. 110.157776

37. Ragel P, Streb S, Feil R, Sahrawy M, Annunziata MG, Lunn JE, Zeeman S, Mérida Á (2013) Loss of starch granule initiation has a deleterious effect on the growth of Arabidopsis plants due to an accumulation of ADP-glucose. Plant Physiol 163:75-85. doi:10.1104/pp.113.223420

38. Flügge UI, Häusler RE, Ludewig F, Gierth M (2011) The role of transporters in supplying energy to plant plastids. J Exp Bot 62:2381-2392. doi:10.1093/jxb/erq361

39. Fettke J, Malinova I, Albrecht T, Hejazi M, Steup M (2011) Glucose-1-phosphate transport into protoplasts and chloroplasts from leaves of Arabidopsis. Plant Physiol 155:1723-1734. doi:10.1104/pp.110.168716

40. Denyer K, Dunlap F, Thorbjørnsen T, Keeling P, Smith AM (1996) The major form of ADP-glucose pyrophosphorylase in maize endosperm is extra-plastidial. Plant Physiol 112:779-785. doi:10.1104/pp.112.2.779

41. Beckles DM, Smith AM, Rees T (2001) A cytosolic ADP-glucose pyrophosphorylase is a feature of graminaceous endosperms, but not of other starch-storing organs. Plant Physiol 125:818-827. doi:10.1104/pp.125.2.818

42. Kirchberger S, Leroch M, Huynen MA, Wahl M, Neuhaus HE, Tjaden J (2007) Molecular and biochemical analysis of the plastidic ADP-glucose transporter (ZmBT1) from Zea mays. J Biol Chem 282:22481-22491. doi:10.1074/jbc.M702484200

43. Kirchberger S, Tjaden J, Neuhaus HE (2008) Characterization of the Arabidopsis Brittle1 transport protein and impact of reduced activity on plant metabolism. Plant J 56:51-63. doi:10.1111/j. 1365-313X.2008.03583.x

44. Geigenberger P (2011) Regulation of starch biosynthesis in response to a fluctuating environment. Plant Physiol 155:1566-1577. doi:10.1104/pp.110.170399

45. Sowokinos JR, Preiss J (1982) Pyrophosphorylases in Solanum tuberosum III. Purification, physical, and catalytic properties of
ADPglucose pyrophosphorylase in potatoes. Plant Physiol 69:1459-1466. doi:10.1104/pp.69.6.1459

46. Sikka VK, Choi SB, Kavakli IH, Sakulsingharoj C, Gupta S, Ito H, Okita TW (2001) Subcellular compartmentation and allosteric regulation of the rice endosperm ADPglucose pyrophosphorylase. Plant Sci 161:461-468. doi:10.1016/S01689452(01)00431-9

47. Fu Y, Ballicora MA, Leykam JF, Preiss J (1998) Mechanism of reductive activation of potato tuber ADP-glucose pyrophosphorylase. J Biol Chem 273:25045-25052. doi:10.1074/jbc.273. 39.25045

48. Tiessen A, Hendriks JHM, Stitt M, Branscheid A, Gibon Y, Farré EM, Geigenberger P (2002) Starch synthesis in potato tubers is regulated by post-translational redox modification of ADP-glucose pyrophosphorylase. Plant Cell 14:2191-2213. doi:10.1105/tpc.003640.2192

49. Hädrich N, Hendriks JHM, Kötting O, Arrivault S, Feil R, Zeeman SC, Gibon Y, Schulze WX, Stitt M, Lunn JE (2012) Mutagenesis of cysteine 81 prevents dimerization of the APS1 subunit of ADP-glucose pyrophosphorylase and alters diurnal starch turnover in Arabidopsis thaliana leaves. Plant J 70:231-242. doi:10.1111/j.1365-313X.2011.04860.x

50. Stark DM, Timmerman KP, Barry GF, Preiss J, Kishore GM (1992) Regulation of the amount of starch in plant tissues by ADP glucose pyrophosphorylase. Science 258:287-292

51. Sweetlove LJ, Burrell MM, Rees T (1996) Starch metabolism in tubers of transgenic potato (Solanum tuberosum) with increased ADPglucose pyrophosphorylase. Biochem J 492:493-498. doi:10.1042/bj3200493

52. Giroux MJ, Shaw J, Barry G, Cobb BG, Greene T, Okita T, Hannah LC (1996) A single mutation that increases maize seed weight. Proc Natl Acad Sci 93:5824-5829. doi:10.1073/pnas.93. 12.5824

53. Smidansky ED, Clancy M, Meyer FD, Lanning SP, Blake NK, Talbert LE, Giroux MJ (2002) Enhanced ADP-glucose pyrophosphorylase activity in wheat endosperm increases seed yield. Proc Natl Acad Sci 99:1724-1729. doi:10.1073/pnas. 022635299

54. Sakulsingharoj C, Choi SB, Hwang SK, Edwards GE, Bork J, Meyer CR, Preiss J, Okita TW (2004) Engineering starch biosynthesis for increasing rice seed weight: the role of the cytoplasmic ADP-glucose pyrophosphorylase. Plant Sci 167:1323-1333. doi:10.1016/j.plantsci.2004.06.028

55. Ihemere U, Arias-Garzon D, Lawrence S, Sayre R (2006) Genetic modification of cassava for enhanced starch production. Plant Biotechnol J 4:453-465. doi:10.1111/j.1467-7652.2006. 00195.x

56. Wang Z, Chen X, Wang J, Liu T, Liu Y, Zhao L, Wang G (2007) Increasing maize seed weight by enhancing the cytoplasmic ADP-glucose pyrophosphorylase activity in transgenic maize plants. Plant Cell Tissue Organ Cult 88:83-92. doi:10. 1007/s11240-006-9173-4

57. Kang G, Liu G, Peng X, Wei L, Wang C, Zhu Y, Ma Y, Jiang Y, Guo $T$ (2013) Increasing the starch content and grain weight of common wheat by overexpression of the cytosolic AGPase large subunit gene. Plant Physiol Biochem 73:93-98. doi:10.1016/j. plaphy.2013.09.003

58. Tuncel A, Okita TW (2013) Improving starch yield in cereals by over-expression of ADPglucose pyrophosphorylase: expectations and unanticipated outcomes. Plant Sci 211:52-60. doi:10. 1016/j.plantsci.2013.06.009

59. Lombard V, Ramulu HG, Drula E, Coutinho PM, Henrissat B (2014) The carbohydrate-active enzymes database (CAZy) in 2013. Nucleic Acids Res 42:490-495. doi:10.1093/nar/gkt1178

60. Liu H, Yu G, Wei B, Wang Y, Zhang J, Hu Y, Liu Y, Yu G, Zhang H, Huang Y (2015) Identification and phylogenetic 
analysis of a novel starch synthase in maize. Front Plant Sci 6:1013. doi:10.3389/fpls.2015.01013

61. Leterrier M, Holappa LD, Broglie KE, Beckles DM (2008) Cloning, characterisation and comparative analysis of a starch synthase IV gene in wheat: functional and evolutionary implications. BMC Plant Biol 8:98-119. doi:10.1186/1471-2229-8-98

62. Buschiazzo A, Ugalde JE, Guerin ME, Shepard W, Ugalde RA, Alzari PM (2004) Crystal structure of glycogen synthase: homologous enzymes catalyze glycogen synthesis and degradation. EMBO J 23:3196-3205. doi:10.1038/sj.emboj.7600324

63. Sheng F, Jia X, Yep A, Preiss J, Geiger JH (2009) The crystal structures of the open and catalytically competent closed conformation of Escherichia coli glycogen synthase. J Biol Chem 284:17796-17807. doi:10.1074/jbc.M809804200

64. Momma M, Fujimoto Z (2012) Interdomain disulfide bridge in the rice granule bound starch synthase I catalytic domain as elucidated by X-ray structure analysis. Biosci Biotechnol Biochem 76:1591-1595. doi:10.1271/bbb.120305

65. Cuesta-Seijo JA, Nielsen MM, Marri L, Tanaka H, Beeren SR, Palcic MM (2013) Structure of starch synthase I from barley: insight into regulatory mechanisms of starch synthase activity. Acta Crystallogr D 69:1013-1025. doi:10.1107/S09074449 1300440X

66. Furukawa K, Tagaya M, Preiss J, Fukui T (1990) Identification of lysine 15 at the active site in Escherichia coli glycogen synthase. J Biol Chem 265:2086-2090

67. Furukawa K, Tagaya M, Tanizawa K, Fukui T (1993) Role of the conserved Lys-X-Gly-Gly sequence at the ADP-glucosebinding site in Escherichia coli glycogen synthase. J Biol Chem 268:23837-23842

68. Edwards A, Borthakur A, Bornemann S, Venail J, Denyer K, Waite D, Fulton D, Smith A, Martin C (1999) Specificity of starch synthase isoforms from potato. Eur J Biochem 266:724-736. doi:10.1046/j.1432-1327.1999.00861.x

69. Imparl-Radosevich JM, Keeling PL, Guan H (1999) Essential arginine residues in maize starch synthase IIa are involved in both ADP-glucose and primer binding. FEBS Lett 457:357-362. doi:10.1016/S0014-5793(99)01066-2

70. Nichols DJ, Keeling PL, Spalding M, Guan H (2000) Involvement of conserved aspartate and glutamate residues in the catalysis and substrate binding of maize starch synthase. Biochemistry 39:7820-7825. doi:10.1021/bi000407g

71. Yep A, Ballicora MA, Preiss J (2006) The ADP-glucose binding site of the Escherichia coli glycogen synthase. Arch Biochem Biophys 453:188-196. doi:10.1016/j.abb.2006.07.003

72. Busi MV, Palopoli N, Valdez HA, Fornasari MS, Wayllace NZ, Gomez-Casati DF, Parisi G, Ugalde RA (2008) Functional and structural characterization of the catalytic domain of the starch synthase III from Arabidopsis thaliana. Proteins 70:31-40. doi:10.1002/prot.21469

73. Hennen-Bierwagen TA, Liu F, Marsh RS, Kim S, Gan Q, Tetlow IJ, Emes MJ, James MG, Myers AM (2008) Starch biosynthetic enzymes from developing maize endosperm associate in multisubunit complexes. Plant Physiol 146:1892-1908. doi:10.1104/pp.108.116285

74. Hennen-Bierwagen TA, Lin Q, Grimaud F, Planchot V, Keeling PL, James MG, Myers AM (2009) Proteins from multiple metabolic pathways associate with starch biosynthetic enzymes in high molecular weight complexes: a model for regulation of carbon allocation in maize amyloplasts. Plant Physiol 149:1541-1559. doi:10.1104/pp.109.135293

75. Gámez-Arjona FM, Raynaud S, Ragel P, Mérida A (2014) Starch synthase 4 is located in the thylakoid membrane and interacts with plastoglobule-associated proteins in Arabidopsis. Plant J 80:305-316. doi:10.1111/tpj.12633
76. Valdez HA, Busi MV, Wayllace NZ, Parisi G, Ugalde RA, Gomez-Casati DF (2008) Role of the N-terminal starch-binding domains in the kinetic properties of starch synthase III from Arabidopsis thaliana. Biochemistry 47:3026-3032. doi:10.1021/ bi702418h

77. Wayllace NZ, Valdez HA, Ugalde RA, Busi MV, Gomez-Casati DF (2010) The starch-binding capacity of the noncatalytic SBD2 region and the interaction between the $\mathrm{N}$ - and $\mathrm{C}$-terminal domains are involved in the modulation of the activity of starch synthase III from Arabidopsis thaliana. FEBS J 277:428-440. doi:10.1111/j.1742-4658.2009.07495.x

78. Yan HB, Pan XX, Jiang HW, Wu GJ (2009) Comparison of the starch synthesis genes between maize and rice: copies, chromosome location and expression divergence. Theor Appl Genet 119:815-825. doi:10.1007/s00122-009-1091-5

79. Ohdan T, Francisco PB, Sawada T, Hirose T, Terao T, Satoh H, Nakamura Y (2005) Expression profiling of genes involved in starch synthesis in sink and source organs of rice. J Exp Bot 56:3229-3244. doi:10.1093/jxb/eri292

80. Zhang G, Cheng Z, Zhang X, Guo X, Su N, Jiang L (2011) Double repression of soluble starch synthase genes SSIIa and SSIIIa in rice (Oryza sativa L.) uncovers interactive effects on the physicochemical properties of starch. Genome 54(459): 448-459. doi:10.1139/G11-010

81. Jiang H, Dian W, Liu F, Wu P (2004) Molecular cloning and expression analysis of three genes encoding starch synthase II in rice. Planta 218:1062-1070. doi:10.1007/s00425-003-1189-y

82. Cheng J, Khan MA, Qiu W-M, Li J, Zhou H, Zhang Q, Guo W et al (2012) Diversification of genes encoding granule-bound starch synthase in monocots and dicots is marked by multiple genome-wide duplication events. PLoS One 7:e30088. doi:10. 1371/journal.pone.0030088

83. Vrinten PL, Nakamura T (2000) Wheat granule-bound starch synthase I and II are encoded by separate genes that are expressed in different tissues. Plant Physiol 122:255-264. doi:10.1104/pp.122.1.255

84. Edwards A, Vincken J-P, Suurs LCJM, Visser RGF, Zeeman S, Smith A, Martin C (2002) Discrete forms of amylose are synthesized by isoforms of GBSSI in pea. Plant Cell 14:1767-1785. doi: $10.1105 /$ tpc. 002907

85. Sprague GF, Brimhall B, Hixon RM (1943) Some effects of the waxy gene in corn on properties of the endosperm starch. Agron $\mathrm{J}$ 35:817-823. doi:10.2134/agronj1943.00021962003500090008x

86. Shure M, Wessler S, Fedoroff N (1983) Molecular identification and isolation of the Waxy locus in maize. Cell 35:225-233. doi:10.1016/0092-8674(83)90225-8

87. Sano Y (1984) Differential regulation of waxy gene expression in rice endosperm. Theor Appl Genet 68:467-473. doi:10.1007/ BF00254822

88. Wang Z-Y, Zheng F-Q, Shen G-Z, Gao J-P, Snustad DP, Li M-G, Zhang J-L, Hong M-M (1995) The amylose content in rice endosperm is related to the post-transcriptional regulation of the waxy gene. Plant J 7:613-622. doi:10.1046/j.1365-313X.1995. 7040613.x

89. Nakamura T, Yamamori M, Hirano H, Hidaka S, Nagamine T (1995) Production of waxy (amylose-free) wheats. Mol Gen Genet 248:253-259. doi:10.1007/BF02191591

90. Patron NJ, Smith AM, Fahy BF, Hylton CM, Naldrett MJ, Rossnagel BG, Denyer K (2002) The altered pattern of amylose accumulation in the endosperm of low-amylose barley cultivars is attributable to a single mutant allele of granule-bound starch synthase I with a deletion in the $5^{\prime}$-non-coding region. Plant Physiol 130:190-198. doi:10.1104/pp.005454

91. Konishi Y, Nojima H, Okuno K, Asaoka M, Fuwa H (1985) Characterization of starch granules from waxy, nonwaxy, and 
hybrid seeds of Amaranthus hypochondriacus L. Agric Biol Chem 49:1965-1971. doi:10.1271/bbb1961.49.1965

92. Hovenkamp-Hermelink JHM, Jacobsen E, Ponstein AS, Visser RGF, Vos-Scheperkeuter GH, Bijmolt EW, de Vries JN, Witholt B, Feenstra WJ (1987) Isolation of an amylose-free starch mutant of the potato (Solanum tuberosum L.). Theor Appl Genet 75:217-221. doi:10.1007/BF00249167

93. Jacobsen E, Hovenkamp-Hermelink JHM, Krijgsheld HT, Nijdam H, Pijnacker LP, Witholt B, Feenstra WJ (1989) Phenotypic and genotypic characterization of an amylose-free starch mutant of the potato. Euphytica 44:43-48. doi:10.1007/BF00022597

94. Denyer K, Baber LM, Burton R, Hedley CL, Hylton CM, Johnson S, Jones DA et al (1995) The isolation and characterization of novel low-amylose mutants of Pisum sativum L. Plant Cell Environ 18:1019-1026. doi:10.1111/j.1365-3040.1995. tb00612.x

95. Seung D, Soyk S, Coiro M, Maier BA, Eicke S, Zeeman SC (2015) PROTEIN TARGETING TO STARCH is required for localising GRANULE-BOUND STARCH SYNTHASE to starch granules and for normal amylose synthesis in Arabidopsis. PLoS Biol 13:e1002080. doi:10.1371/journal.pbio.1002080

96. Delrue B, Fontaine T, Routier F, Decq A, Wieruszeski JM, Van Den Koornhuyse N, Maddelein ML, Fournet B, Ball S (1992) Waxy Chlamydomonas reinhardtii: monocellular algal mutants defective in amylose biosynthesis and granule-bound starch synthase activity accumulate a structurally modified amylopectin. J Bacteriol 174:3612-3620

97. Ral J-P, Colleoni C, Wattebled F, Dauvillée D, Nempont C, Deschamps P, Li Z et al (2006) Circadian clock regulation of starch metabolism establishes GBSSI as a major contributor to amylopectin synthesis in Chlamydomonas reinhardtii. Plant Physiol 142:305-317. doi:10.1104/pp.106.081885

98. Tatge H, Marshall J, Martin C, Edwards EA, Smith AM (1999) Evidence that amylose synthesis occurs within the matrix of the starch granule in potato tubers. Plant Cell Environ 22:543-550

99. Denyer K, Waite D, Motawia S, Møller BL, Smith AM (1999) Granule-bound starch synthase I in isolated starch granules elongates malto-oligosaccharides processively. Biochem $\mathbf{J}$ 340:183-191. doi:10.1042/0264-6021:3400183

100. Van Wal M, De D'Hulst C, Vincken JP, Buléon A, Visser R, Ball S (1998) Amylose is synthesized in vitro by extension of and cleavage from amylopectin. J Biol Chem 273:22232-22240. doi:10.1074/jbc.273.35.22232

101. Zeeman SC, Smith SM, Smith AM (2002) The priming of amylose synthesis in Arabidopsis leaves. Plant Physiol 128:1069-1076. doi:10.1104/pp.010640

102. Denyer K, Clarke B, Hylton C, Tatge H, Smith AM (1996) The elongation of amylose and amylopectin chains in isolated starch granules. Plant J 10:1135-1143. doi:10.1046/j.1365-313X.1996. 10061135.x

103. Denyer K, Sidebottom C, Hylton CM, Smith AM (1993) Soluble isoforms of starch synthase and starch branching enzyme also occur within starch granules in developing pea embryos. Plant $\mathbf{J}$ 4:191-198. doi:10.1046/j.1365-313X.1993.04010191.x

104. Lohmeier-Vogel EM, Kerk D, Nimick M, Wrobel S, Vickerman L, Muench DG, Moorhead GBG (2008) Arabidopsis At5g39790 encodes a chloroplast-localized, carbohydrate-binding, coiledcoil domain-containing putative scaffold protein. BMC Plant Biol 8:120. doi:10.1186/1471-2229-8-120

105. Yeh JY, Garwood DL, Shannon JC (1981) Characterization of starch from maize endosperm mutants. Starch/Stärke 33:222-230

106. Klucinec JD, Thompson DB (2002) Structure of amylopectins from ae-containing maize starches. Cereal Chem 79:19-23. doi:10.1094/CCHEM.2002.79.1.19

107. Reddy KR, Ali SZ, Bhattacharya KR (1993) The fine structure of rice-starch amylopectin and its relation to the texture of cooked rice. Carbohydr Polym 22:267-275. doi:10.1016/01448617(93)90130-V

108. Ahuja G, Jaiswal S, Hucl P, Chibbar RN (2014) Wheat genome specific granule-bound starch synthase I differentially influence grain starch synthesis. Carbohydr Polym 114:87-94. doi:10. 1016/j.carbpol.2014.08.004

109. Inouchi N, Glover DV, Fuwa H (1987) Chain length distribution of amylopectins of several single mutants and the normal counterpart, and sugary-1 phytoglycogen in maize (Zea mays L.). Starch/Stärke 39:259-266. doi:10.1002/star.19870390802

110. Bertoft E, Piyachomkwan K, Chatakanonda P, Sriroth K (2008) Internal unit chain composition in amylopectins. Carbohydr Polym 74:527-543. doi:10.1016/j.carbpol.2008.04.011

111. Crofts N, Abe K, Aihara S, Itoh R, Nakamura Y, Itoh K, Fujita N (2012) Lack of starch synthase IIIa and high expression of granule-bound starch synthase I synergistically increase the apparent amylose content in rice endosperm. Plant Sci 193-194:62-69. doi:10.1016/j.plantsci.2012.05.006

112. Wattebled F, Buléon A, Bouchet B, Ral JP, Liénard L, Delvallé D, Binderup K, Dauvillée D, Ball S, D’Hulst C (2002) Granulebound starch synthase I: a major enzyme involved in the biogenesis of B-crystallites in starch granules. Eur $\mathrm{J}$ Biochem 269:3810-3820. doi:10.1046/j.1432-1033.2002.03072.x

113. Maddelein M-L, Libessarts N, Bellanger F, Delrue B, Hulst CD, Van Den Koornhuyse N, Fontaine T, Wieruszeski J-M, Decq A, Ball S (1994) Toward an understanding of the biogenesis of the starch granule. J Biol Chem 269:25150-25157

114. Fulton DC, Edwards A, Pilling E, Robinson HL, Fahy B, Seale $\mathrm{R}$, Kato L et al (2002) Role of granule-bound starch synthase in determination of amylopectin structure and starch granule morphology in potato. J Biol Chem 277:10834-10841. doi:10. 1074/jbc.M111579200

115. Tetlow IJ, Emes MJ (2011) Starch biosynthesis in higher plants: the enzymes of starch synthesis. In: Murray M-Y (ed) Comprehensive biotechnology, 2nd edn. Elsevier, Amsterdam, pp 47-65. doi:10.1016/B978-0-08-088504-9.00538-9

116. Roldán I, Wattebled F, Lucas MM, Delvallé D, Planchot V, Jiménez S, Pérez R, Ball S, D’Hulst C, Mérida A (2007) The phenotype of soluble starch synthase IV defective mutants of Arabidopsis thaliana suggests a novel function of elongation enzymes in the control of starch granule formation. Plant J 49:492-504. doi:10.1111/j.1365-313X.2006.02968.x

117. Szydlowski N, Ragel P, Raynaud S, Lucas MM, Roldán I, Montero M, Muñoz FJ et al (2009) Starch granule initiation in Arabidopsis requires the presence of either class IV or class III starch synthases. Plant Cell 21:2443-2457. doi:10.1105/tpc.109. 066522

118. Crumpton-Taylor M, Pike M, Lu K-J, Hylton CM, Feil R, Eicke S, Lunn JE, Zeeman SC, Smith AM (2013) Starch synthase 4 is essential for coordination of starch granule formation with chloroplast division during Arabidopsis leaf expansion. New Phytol 200:1064-1075. doi:10.1111/nph.12455

119. Zhang X, Szydlowski N, Delvallé D, D'Hulst C, James MG, Myers AM (2008) Overlapping functions of the starch synthases SSII and SSIII in amylopectin biosynthesis in Arabidopsis. BMC Plant Biol 8:96. doi:10.1186/1471-2229-8-96

120. Delatte T, Trevisan M, Parker ML, Zeeman SC (2005) Arabidopsis mutants Atisal and Atisa2 have identical phenotypes and lack the same multimeric isoamylase, which influences the branch point distribution of amylopectin during starch synthesis. Plant J 41:815-830. doi:10.1111/j.1365-313X.2005.02348.x

121. Streb S, Delatte T, Umhang M, Eicke S, Schorderet M, Reinhardt D, Zeeman SC (2008) Starch granule biosynthesis in Arabidopsis is abolished by removal of all debranching enzymes but restored by the subsequent removal of an endoamylase. Plant Cell 20:3448-3466. doi:10.1105/tpc.108.063487 
122. Pfister B, Lu K-J, Eicke S, Feil R, Lunn JE, Streb S, Zeeman SC (2014) Genetic evidence that chain length and branch point distributions are linked determinants of starch granule formation in Arabidopsis. Plant Physiol 165:1457-1474. doi:10.1104/pp. 114.241455

123. Tetlow IJ, Wait R, Lu Z, Akkasaeng R, Bowsher CG, Esposito S, Kosar-Hashemi B, Morell MK, Emes MJ (2004) Protein phosphorylation in amyloplasts regulates starch branching enzyme activity and protein-protein interactions. Plant Cell 16:694-708. doi:10.1105/tpc.017400

124. Tetlow IJ, Beisel KG, Cameron S, Makhmoudova A, Liu F, Bresolin NS, Wait R, Morell MK, Emes MJ (2008) Analysis of protein complexes in wheat amyloplasts reveals functional interactions among starch biosynthetic enzymes. Plant Physiol 146:1878-1891. doi:10.1104/pp.108.116244

125. Liu F, Makhmoudova A, Lee EA, Wait R, Emes MJ, Tetlow IJ (2009) The amylose extender mutant of maize conditions novel protein-protein interactions between starch biosynthetic enzymes in amyloplasts. J Exp Bot 60:4423-4440. doi:10.1093/ jxb/erp297

126. Ahmed Z, Tetlow IJ, Ahmed R, Morell MK, Emes MJ (2015) Protein-protein interactions among enzymes of starch biosynthesis in high-amylose barley genotypes reveal differential roles of heteromeric enzyme complexes in the synthesis of $\mathrm{A}$ and $\mathrm{B}$ granules. Plant Sci 233:95-106. doi:10.1016/j.plantsci.2014.12. 016

127. Crofts N, Abe N, Oitome NF, Matsushima R, Hayashi M, Tetlow IJ, Emes MJ, Nakamura Y, Fujita N (2015) Amylopectin biosynthetic enzymes from developing rice seed form enzymatically active protein complexes. J Exp Bot 66:4469-4482. doi: $10.1093 /$ jxb/erv212

128. Cao H, Imparl-Radosevich J, Guan H, Keeling PL, James MG, Myers AM (1999) Identification of the soluble starch synthase activities of maize endosperm. Plant Physiol 120:205-215

129. Knight ME, Harn C, Lilley CER, Guan H, Singletary GW, MuForster C, Wasserman BP, Keeling PL (1998) Molecular cloning of starch synthase I from maize (W64) endosperm and expression in Escherichia coli. Plant J 14:613-622. doi:10.1046/j. 1365-313X.1998.00150.x

130. Abel GJW, Springer F, Willmitzer L, Kossmann J (1996) Cloning and functional analysis of a cDNA encoding a novel $139 \mathrm{kDa}$ starch synthase from potato (Solanum tuberosum L.). Plant J 10:981-991

131. Marshall J, Sidebottom C, Debet M, Martin C, Smith AM, Edwards A (1996) Identification of the major starch synthase in the soluble fraction of potato tubers. Plant Cell 8:1121-1135. doi:10.1105/tpc.8.7.1121

132. Tomlinson K, Craig J, Smith AM (1998) Major differences in isoform composition of starch synthase between leaves and embryos of pea (Pisum sativum L.). Planta 204:86-92

133. Kossmann J, Abel GJ, Springer F, Lloyd JR, Willmitzer L (1999) Cloning and functional analysis of a cDNA encoding a starch synthase from potato (Solanum tuberosum L.) that is predominantly expressed in leaf tissue. Planta 208:503-511

134. Szydlowski N, Ragel P, Hennen-Bierwagen TA, Planchot V, Myers AM, Mérida A, D'Hulst C, Wattebled F (2011) Integrated functions among multiple starch synthases determine both amylopectin chain length and branch linkage location in Arabidopsis leaf starch. J Exp Bot 62:4547-4559. doi:10.1093/jxb/ err172

135. Smith SM, Fulton DC, Chia T, Thorneycroft D, Chapple A, Dunstan H, Hylton C, Zeeman SC, Smith AM (2004) Diurnal changes in the transcriptome encoding enzymes of starch metabolism provide evidence for both transcriptional and posttranscriptional regulation of starch metabolism in Arabidopsis leaves. Plant Physiol 136:2687-2699. doi:10.1104/pp.104. 044347

136. Fujita N, Yoshida M, Asakura N, Ohdan T, Miyao A, Hirochika H, Nakamura Y (2006) Function and characterization of starch synthase I using mutants in rice. Plant Physiol 140:1070-1084. doi:10.1104/pp.105.071845.1070

137. McMaugh SJ, Thistleton JL, Anschaw E, Luo J, Konik-Rose C, Wang H, Huang M et al (2014) Suppression of starch synthase I expression affects the granule morphology and granule size and fine structure of starch in wheat endosperm. J Exp Bot 65:2189-2201. doi:10.1093/jxb/eru095

138. Delvallé D, Dumez S, Wattebled F, Roldán I, Planchot V, Berbezy P, Colonna P et al (2005) Soluble starch synthase I: a major determinant for the synthesis of amylopectin in Arabidopsis thaliana leaves. Plant J 43:398-412. doi:10.1111/j. 1365-313X.2005.02462.x

139. Commuri PD, Keeling PL (2001) Chain-length specificities of maize starch synthase I enzyme: studies of glucan affinity and catalytic properties. Plant J 25:475-486

140. Senoura T, Isono N, Yoshikawa M, Asao A, Hamada S, Watanabe K, Ito H, Matsui H (2004) Characterization of starch synthase I and II expressed in early developing seeds of kidney bean (Phaseolus vulgaris L.). Biosci Biotechnol Biochem 68:1949-1960

141. Mu-Forster C, Huang R, Powers JR, Harriman RW, Knight M, Singletary GW, Keeling PL, Wasserman BP (1996) Physical association of starch biosynthetic enzymes with starch granules of maize endosperm. Granule-associated forms of starch synthase I and starch branching enzyme II. Plant Physiol 111:821-829. doi:10.1104/pp.111.3.821

142. Brust H, Orzechowski S, Fettke J, Steup M (2013) Starch synthesizing reactions and paths: in vitro and in vivo studies. J Appl Glycosci 60:3-20. doi:10.5458/jag.jag.JAG-2012_018

143. Brust H, Lehmann T, D'Hulst C, Fettke J (2014) Analysis of the functional interaction of Arabidopsis starch synthase and branching enzyme isoforms reveals that the cooperative action of SSI and BEs results in glucans with polymodal chain length distribution similar to amylopectin. PLoS One 9:e102364. doi:10.1371/journal.pone.0102364

144. Cuesta-Seijo JA, Nielsen MM, Ruzanski C, Krucewicz K, Beeren SR, Rydhal MG, Yoshimura Y et al (2016) In vitro biochemical characterization of all barley endosperm starch synthases. Front Plant Sci 6:1-17. doi:10.3389/fpls.2015.01265

145. Glaring MA, Skryhan K, Kötting O, Zeeman SC, Blennow A (2012) Comprehensive survey of redox sensitive starch metabolising enzymes in Arabidopsis thaliana. Plant Physiol Biochem 58:89-97. doi:10.1016/j.plaphy.2012.06.017

146. Edwards A, Marshall J, Sidebottom C, Visser RGF, Smith AM, Martin C (1995) Biochemical and molecular characterization of a novel starch synthase from potato tubers. Plant J 8:283-294. doi:10.1046/j.1365-313X.1995.08020283.x

147. Edwards A, Fulton DC, Hylton CM, Jobling SA, Gidley M, Ro U, Martin C, Smith AM (1999) A combined reduction in activity of starch synthases II and III of potato has novel effects on the starch of tubers. Plant J 17:251-261. doi:10.1046/j.1365-313X. 1999.00371.x

148. Lloyd JR, Landschütze V, Kossmann J (1999) Simultaneous antisense inhibition of two starch-synthase isoforms in potato tubers leads to accumulation of grossly modified amylopectin. Biochem J 338:515-521. doi:10.1042/bj3380515

149. Craig J, Lloyd JR, Tomlinson K, Barber L, Edwards A, Wang TL, Martin C, Hedley CL, Smith AM (1998) Mutations in the gene encoding starch synthase II profoundly alter amylopectin structure in pea embryos. Plant Cell 10:413-426. doi:10.1105/ tpc.10.3.413 
150. Yamamori M, Fujita S, Hayakawa K, Matsuki J, Yasui T (2000) Genetic elimination of a starch granule protein, SGP-1, of wheat generates an altered starch with apparent high amylose. Theor Appl Genet 101:21-29. doi:10.1007/s001220051444

151. Morell MK, Kosar-Hashemi B, Cmiel M, Samuel MS, Chandler P, Rahman S, Buleon A, Batey IL, Li Z (2003) Barley sex6 mutants lack starch synthase IIa activity and contain a starch with novel properties. Plant J 34:173-185. doi:10.1046/j.1365313X.2003.01712.x

152. Umemoto T, Nakamura Y, Satoh H, Terashima K (1999) Differences in amylopectin structure between two rice varieties in relation to the effects of temperature. Starch/Stärke 2-3:58-62. doi:10.1002/(SICI)1521-379X(199903)51:2<58:AIDSTAR58>3.0.CO;2-J

153. Umemoto T, Yano M, Satoh H, Shomura A, Nakamura Y (2002) Mapping of a gene responsible for the difference in amylopectin structure between japonica-type and indica-type rice varieties. Theor Appl Genet 104:1-8. doi:10.1007/s001220200000

154. Zhang X, Colleoni C, Ratushna V, Sirghie-Colleoni M, James MG, Myers AM (2004) Molecular characterization demonstrates that the Zea mays gene sugary2 codes for the starch synthase isoform SSIIa. Plant Mol Biol 54:865-879. doi:10.1007/s11103004-0312-1

155. Nakamura Y, Francisco PB, Hosaka Y, Sato A, Sawada T, Kubo A, Fujita N (2005) Essential amino acids of starch synthase IIa differentiate amylopectin structure and starch quality between japonica and indica rice varieties. Plant Mol Biol 58:213-227. doi:10.1007/s1

156. Wang Y-J, White P, Pollak L, Jane J (1993) Characterization of starch structures of 17 maize endosperm mutant genotypes with Oh43 inbred line background. Cereal Chem 70:171-179

157. Fujita N, Yoshida M, Kondo T, Saito K, Utsumi Y, Tokunaga T, Nishi A et al (2007) Characterization of SSIIIa-deficient mutants of rice: the function of SSIIIa and pleiotropic effects by SSIIIa deficiency in the rice endosperm. Plant Physiol 144:2009-2023. doi:10.1104/pp.107.102533

158. Zhang X, Myers AM, James MG (2005) Mutations affecting starch synthase III in Arabidopsis alter leaf starch structure and increase the rate of starch synthesis. Plant Physiol 138:663-674. doi:10.1104/pp.105.060319.1

159. Li Z, Li D, Du X, Wang H, Larroque O, Jenkins CLD, Jobling SA, Morell MK (2011) The barley amol locus is tightly linked to the starch synthase IIIa gene and negatively regulates expression of granule-bound starch synthetic genes. J Exp Bot 62:5217-5231. doi:10.1093/jxb/err239

160. Lin Q, Huang B, Zhang M, Zhang X, Rivenbark J, Lappe RL, James MG, Myers AM, Hennen-Bierwagen TA (2012) Functional interactions between starch synthase III and isoamylasetype starch-debranching enzyme in maize endosperm. Plant Physiol 158:679-692. doi:10.1104/pp.111.189704

161. Jobling SA, Westcott RJ, Tayal A, Jeffcoat R, Schwall GP (2002) Production of a freeze-thaw-stable potato starch by antisense inhibition of three starch synthase genes. Nat Biotechnol 20:295-299. doi:10.1038/nbt0302-295

162. Boyer CD, Preiss J (1981) Evidence for independent genetic control of the multiple forms of maize endosperm branching enzymes and starch synthases. Plant Physiol 67:1141-1145. doi:10.1104/pp.67.6.1141

163. Toyosawa Y, Kawagoe Y, Matsushima R, Crofts N, Ogawa M, Fukuda M, Kumamaru T et al (2016) Deficiency of starch synthase IIIa and IVb alters starch granule morphology from polyhedral to spherical in rice endosperm. Plant Physiol 170:1255-1270. doi:10.1104/pp.15.01232

164. Crumpton-Taylor M, Grandison S, Png KMY, Bushby AJ, Smith AM (2012) Control of starch granule numbers in
Arabidopsis chloroplasts. Plant Physiol 158:905-916. doi:10. 1104/pp.111.186957

165. Gámez-Arjona FM, Li J, Raynaud S, Baroja-Fernández E, Muñoz FJ, Ovecka M, Ragel P, Bahaji A, Pozueta-Romero J, Mérida Á (2011) Enhancing the expression of starch synthase class IV results in increased levels of both transitory and longterm storage starch. Plant Biotechnol J 9:1049-1060. doi:10. 1111/j.1467-7652.2011.00626.x

166. Myers AM, James MG, Lin Q, Yi G, Stinard PS, HennenBierwagen TA, Becraft PW (2011) Maize opaque5 encodes monogalactosyldiacylglycerol synthase and specifically affects galactolipids necessary for amyloplast and chloroplast function. Plant Cell 23:2331-2347. doi:10.1105/tpc.111.087205

167. Kawagoe Y (2013) The characteristic polyhedral, sharp-edged shape of compound-type starch granules in rice endosperm is achieved via the septum-like structure of the amyloplast. J Appl Glycosci 60:29-36. doi:10.5458/jag.jag.JAG-2012

168. Ugalde JE, Parodi AJ, Ugalde RA (2003) De novo synthesis of bacterial glycogen: Agrobacterium tumefaciens glycogen synthase is involved in glucan initiation and elongation. Proc Natl Acad Sci 100:10659-10663. doi:10.1073/pnas.1534787100

169. Lomako J, Lomako WM, Whelan WJ (1988) A self-glucosylating rabbit protein glycogen is the primer for rabbit muscle glycogen biosynthesis. FASEB J 2:3097-3103

170. Pitcher J, Smythe C, Cohen P (1988) Glycogenin is the priming glucosyltransferase required for the initiation of glycogen biogenesis in rabbit skeletal muscle. Eur J Biochem 176:391-395. doi:10.1111/j.1432-1033.1988.tb14294.x

171. Linden JC, Schilling N, Brackenhofer H, Kandler O (1975) Asymmetric labelling of maltose during photosynthesis in ${ }^{14} \mathrm{CO}_{2}$. Zeitschrift für Pflanzenphysiologie 76:176-181. doi:10. 1016/S0044-328X(75)80035-3

172. Szecowka M, Heise R, Tohge T, Nunes-Nesi A, Vosloh D, Huege J, Feil R et al (2013) Metabolic fluxes in an illuminated Arabidopsis rosette. Plant Cell 25:694-714. doi:10.1105/tpc. 112.106989

173. Rothschild A, Tandecarz JS (1994) UDP-glucose:protein transglucosylase in developing maize endosperm. Plant Sci 98:119-127

174. Singh D, Lomako J, Lomako W, Whealan W, Meyer H, Serwe M, Metzger J (1995) Beta-glucosylarginine-a new glucose protein bond in a self-glucosylating protein from sweet corn. FEBS Lett 376:61-64

175. Langeveld SMJ, Vennik M, Kottenhagen M, Van Wijk R, Buijk A, Kijne JW, de Pater S (2002) Glucosylation activity and complex formation of two classes of reversibly glycosylated polypeptides. Plant Physiol 129:278-289. doi:10.1104/pp.010720

176. Drakakaki G, Zabotina O, Delgado I, Robert S, Keegstra K, Raikhel N (2006) Arabidopsis reversibly glycosylated polypeptides 1 and 2 are essential for pollen development. Plant Physiol 142:1480-1492. doi:10.1104/pp.106.086363

177. Chatterjee M, Berbezy P, Vyas D, Coates S, Barsby T (2005) Reduced expression of a protein homologous to glycogenin leads to reduction of starch content in Arabidopsis leaves. Plant Sci 168:501-509. doi:10.1016/j.plantsci.2004.09.015

178. Tetlow IJ, Emes MJ (2014) A review of starch-branching enzymes and their role in amylopectin biosynthesis. IUBMB Life 66:546-558. doi:10.1002/iub.1297

179. Dumez S, Wattebled F, Dauvillee D, Delvalle D, Planchot V, Ball SG, D'Hulst C (2006) Mutants of Arabidopsis lacking starch branching enzyme II substitute plastidial starch synthesis by cytoplasmic maltose accumulation. Plant Cell 18:2694-2709. doi:10.1105/tpc.105.037671

180. Gao M, Fisher DK, Kim K-N, Shannon JC, Guiltinan MJ (1996) Evolutionary conservation and expression patterns of maize starch branching enzyme I and IIb genes suggests isoform 
specialization. Plant Mol Biol 30:1223-1232. doi:10.1007/ BF00019554

181. Gao M, Fisher DK, Kim K-N, Shannon JC, Guiltinan MJ (1997) lndependent genetic control of maize starch-branching enzymes IIa and llb. Plant Physiol 114:69-78. doi:10.1104/pp.114.1.69

182. Yamanouchi H, Nakamura Y (1992) Organ specificity of isoforms of starch branching enzyme (Q-enzyme) in rice. Plant Cell Physiol 33:985-991

183. Sun C, Sathish P, Ahlandsberg S, Jansson C (1998) The two genes encoding starch-branching enzymes IIa and IIb are differentially expressed in barley. Plant Physiol 118:37-49. doi:10. 1104/pp.118.1.37

184. Han Y, Sun FJ, Rosales-Mendoza S, Korban SS (2007) Three orthologs in rice, Arabidopsis, and Populus encoding starch branching enzymes (SBEs) are different from other SBE gene families in plants. Gene 401:123-130. doi:10.1016/j.gene.2007. 06.026

185. Wang X, Xue L, Sun J, Zuo J (2010) The Arabidopsis BE1 gene, encoding a putative glycoside hydrolase localized in plastids, plays crucial roles during embryogenesis and carbohydrate metabolism. J Integr Plant Biol 52:273-288. doi:10.1111/j.17447909.2010.00930.x

186. Takeda Y, Guan HP, Preiss J (1993) Branching of amylose by the branching isoenzymes of maize endosperm. Carbohydr Res 240:253-263. doi:10.1016/0008-6215(93)84188-C

187. Guan HP, Preiss J (1993) Differentiation of the properties of the branching isozymes from maize (Zea mays). Plant Physiol 102:1269-1273. doi:10.1104/pp.102.4.1269

188. Guan H, Li P, Imparl-Radosevich J, Preiss J, Keeling P (1997) Comparing the properties of Escherichia coli branching enzyme and maize branching enzyme. Arch Biochem Biophys 342:92-98. doi:10.1006/abbi.1997.0115

189. Rydberg U, Andersson L, Andersson R, Åman P, Larsson H (2001) Comparison of starch branching enzyme I and II from potato. Eur J Biochem 268:6140-6145. doi:10.1046/j.00142956.2001.02568.x

190. Nakamura Y, Utsumi Y, Sawada T, Aihara S, Utsumi C, Yoshida M, Kitamura S (2010) Characterization of the reactions of starch branching enzymes from rice endosperm. Plant Cell Physiol 51:776-794. doi:10.1093/pcp/pcq035

191. Sawada T, Nakamura Y, Ohdan T, Saitoh A, Francisco PB, Suzuki E, Fujita N et al (2014) Diversity of reaction characteristics of glucan branching enzymes and the fine structure of $\alpha$ glucan from various sources. Arch Biochem Biophys 562:9-21. doi:10.1016/j.abb.2014.07.032

192. Lu K-J, Streb S, Meier F, Pfister B, Zeeman SC (2015) Molecular genetic analysis of glucan branching enzymes from plants and bacteria in Arabidopsis reveals marked differences in their functions and capacity to mediate starch granule formation. Plant Physiol 169:1638-1655. doi:10.1104/pp.15.00792

193. Boyer L, Roussel X, Courseaux A, Ndjindji OM, Lancelon-Pin C, Putaux J-L, Tetlow I et al (2015) Expression of E. coli glycogen branching enzyme in an Arabidopsis mutant devoid of endogenous starch branching enzymes induces the synthesis of starch-like polyglucans. Plant Cell. doi:10.1111/pce.12702

194. Blauth SL, Kim KN, Klucinec J, Shannon JC, Thompson D, Guiltinan M (2002) Identification of mutator insertional mutants of starch-branching enzyme 1 (sbe1) in Zea mays L. Plant Mol Biol 48:287-297. doi:10.1023/A:1013335217744

195. Xia H, Yandeau-Nelson M, Thompson DB, Guiltinan MJ (2011) Deficiency of maize starch-branching enzyme I results in altered starch fine structure, decreased digestibility and reduced coleoptile growth during germination. BMC Plant Biol 11:95. doi:10.1186/1471-2229-11-95

196. Satoh H, Nishi A, Yamashita K, Takemoto Y, Tanaka Y, Hosaka Y, Sakurai A, Fujita N, Nakamura Y (2003) Starch- branching enzyme I-deficient mutation specifically affects the structure and properties of starch in rice endosperm. Plant Physiol 133:1111-1121. doi:10.1104/pp.103.021527

197. Regina A, Kosar-Hashemi B, Li Z, Rampling L, Cmiel M, Gianibelli MC, Konik-Rose C, Larroque O, Rahman S, Morell MK (2004) Multiple isoforms of starch branching enzyme-I in wheat: lack of the major SBE-I isoform does not alter starch phenotype. Funct Plant Biol 31:591-601. doi:10.1071/FP03193

198. Safford R, Jobling SA, Sidebottom CM, Westcott RJ, Cooke D, Tober KJ, Strongitharm BH, Russell AL, Gidley MJ (1998) Consequences of antisense RNA inhibition of starch branching enzyme activity on properties of potato starch. Carbohydr Polym 35:155-168. doi:10.1016/S0144-8617(97)00249-X

199. Hedman KD, Boyer CD (1982) Gene dosage at the amyloseextender locus of maize: effects on the levels of starch branching enzymes. Biochem Genet 20:483-492. doi:10.1007/ BF00484699

200. Mizuno K, Kawasaki T, Shimada H, Satoh H, Kobayashi E, Okumura S, Arai Y, Baba T (1993) Alteration of the structural properties of starch components by the lack of an isoform of starch branching enzyme in rice seeds. J Biol Chem 268:19084-19091

201. Sestili F, Janni M, Doherty A, Botticella E, D’Ovidio R, Masci S, Jones HD, Lafiandra D (2010) Increasing the amylose content of durum wheat through silencing of the SBEIIa genes. BMC Plant Biol 10:144. doi:10.1186/1471-2229-10-144

202. Boyer CD, Damewood PA, Matters GL (1980) Effect of gene dosage at high amylose loci on the properties of the amylopectin fractions of the starches. Starch/Stärke 7:217-222

203. Bhattacharyya MK, Smith AM, Ellis THN, Hedley C, Martin C (1990) The wrinkled-seed character of pea described by Mendel is caused by a transposon-like insertion in a gene encoding starch-branching enzyme. Cell 60:115-122. doi:10.1016/00928674(90)90721-P

204. Regina A, Bird A, Topping D, Bowden S, Freeman J, Barsby T, Kosar-Hashemi B, Li Z, Rahman S, Morell M (2006) Highamylose wheat generated by RNA interference improves indices of large-bowel health in rats. Proc Natl Acad Sci 103:3546-3551. doi:10.1073/pnas.0510737103

205. Regina A, Kosar-Hashemi B, Ling S, Li Z, Rahman S, Morell M (2010) Control of starch branching in barley defined through differential RNAi suppression of starch branching enzyme IIa and IIb. J Exp Bot 61:1469-1482. doi:10.1093/jxb/erq011

206. Nishi A, Nakamura Y, Tanaka N, Satoh H (2001) Biochemical and genetic analysis of the effects of amylose-extender mutation in rice endosperm. Plant Physiol 127:459-472. doi:10.1104/pp. 010127.BEII

207. Butardo VM, Fitzgerald MA, Bird AR, Gidley MJ, Flanagan BM, Larroque O, Resurreccion AP et al (2011) Impact of downregulation of starch branching enzyme IIb in rice by artificial microRNA- and hairpin RNA-mediated RNA silencing. J Exp Bot 62:4927-4941. doi:10.1093/jxb/err188

208. Asai H, Abe N, Matsushima R, Crofts N, Oitome NF, Nakamura Y, Fujita N (2014) Deficiencies in both starch synthase IIIa and branching enzyme IIb lead to a significant increase in amylose in SSIIa-inactive japonica rice seeds. J Exp Bot 65:5497-5507. doi:10.1093/jxb/eru310

209. Tanaka N, Fujita N, Nishi A, Satoh H, Hosaka Y, Ugaki M, Kawasaki S, Nakamura Y (2004) The structure of starch can be manipulated by changing the expression levels of starch branching enzyme IIb in rice endosperm. Plant Biotechnol J 2:507-516. doi:10.1111/j.1467-7652.2004.00097.x

210. Jobling SA, Schwall GP, Westcott RJ, Sidebottom CM, Debet M, Gidley MJ, Jeffcoat R, Safford R (1999) A minor form of starch branching enzyme in potato (Solanum tuberosum L.) tubers has a major effect on starch structure: cloning and 
characterisation of multiple forms of SBE A. Plant J 18:163-171. doi:10.1046/j.1365-313X.1999.00441.x

211. Schwall GP, Safford R, Westcott RJ, Jeffcoat R, Tayal A, Shi YC, Gidley MJ, Jobling SA (2000) Production of very-highamylose potato starch by inhibition of SBE A and B. Nat Biotechnol 18:551-554. doi:10.1038/75427

212. Brummell DA, Watson LM, Zhou J, McKenzie MJ, Hallett IC, Simmons L, Carpenter M, Timmerman-Vaughan GM (2015) Overexpression of STARCH BRANCHING ENZYME II increases short-chain branching of amylopectin and alters the physicochemical properties of starch from potato tuber. BMC Biotechnol 15:28. doi:10.1186/s12896-015-0143-y

213. Blauth SL, Yao Y, Klucinec JD, Shannon JC, Thompson DB, Guilitinan MJ (2001) Identification of mutator insertional mutants of starch-branching enzyme 2a in corn. Plant Physiol 125:1396-1405. doi:10.1104/pp.125.3.1396

214. Yandeau-Nelson MD, Laurens L, Shi Z, Xia H, Smith AM, Guiltinan MJ (2011) Starch-branching enzyme IIa is required for proper diurnal cycling of starch in leaves of maize. Plant Physiol 156:479-490. doi:10.1104/pp.111.174094

215. Zeeman SC, Kossmann J, Smith AM (2010) Starch: its metabolism, evolution, and biotechnological modification in plants. Annu Rev Plant Biol 61:209-234. doi:10.1146/annurev-arplant042809-112301

216. Hizukuri S, Abe J, Hanashiro I (2006) Starch: analytical aspects. In: Eliasson A-C (ed) Carbohydrates in food. CRC Press, Boca Raton, pp 305-390

217. Dinges JR, Colleoni C, James MG, Myers AM (2003) Mutational analysis of the pullulanase-type debranching enzyme of maize indicates multiple functions in starch metabolism. Plant Cell 15:666-680. doi:10.1105/tpc.007575

218. Wattebled F, Dong Y, Dumez S, Delvallé D, Planchot V, Berbezy P, Vyas D et al (2005) Mutants of Arabidopsis lacking a chloroplastic isoamylase accumulate phytoglycogen and an abnormal form of amylopectin. Plant Physiol 138:184-195. doi:10.1104/pp.105.059295.amylopectin-trimming

219. Delatte T, Umhang M, Trevisan M, Eicke S, Thorneycroft D, Smith SM, Zeeman SC (2006) Evidence for distinct mechanisms of starch granule breakdown in plants. J Biol Chem 281:12050-12059. doi:10.1074/jbc.M513661200

220. Yun MS, Umemoto T, Kawagoe Y (2011) Rice debranching enzyme Isoamylase 3 facilitates starch metabolism and affects plastid morphogenesis. Plant Cell Physiol 52:1068-1082. doi: $10.1093 / \mathrm{pcp} / \mathrm{pcr} 058$

221. Kubo A, Fujita N, Harada K, Matsuda T, Satoh H, Nakamura Y (1999) The starch-debranching enzymes isoamylase and pullulanase are both involved in amylopectin biosynthesis in rice endosperm. Plant Physiol 121:399-410. doi:10.1104/pp.121.2. 399

222. Fujita N, Toyosawa Y, Utsumi Y, Higuchi T, Hanashiro I, Ikegami A, Akuzawa S et al (2009) Characterization of pullulanase (PUL)-deficient mutants of rice (Oryza sativa L.) and the function of PUL on starch biosynthesis in the developing rice endosperm. J Exp Bot 60:1009-1023. doi:10.1093/jxb/ern349

223. Wattebled F, Planchot V, Dong Y, Szydlowski N, Pontoire B, Devin A, Ball S, D'Hulst C (2008) Further evidence for the mandatory nature of polysaccharide debranching for the aggregation of semicrystalline starch and for overlapping functions of debranching enzymes in Arabidopsis leaves. Plant Physiol 148:1309-1323. doi:10.1104/pp.108.129379

224. Pan D, Nelson OE (1984) A debranching enzyme deficiency in endosperms of the sugary-1 mutants of maize. Plant Physiol 74:324-328

225. James MG, Robertson DS, Myers AM (1995) Characterization of the maize gene sugary1, a determinant of starch composition in kernels. Plant Cell 7:417-429. doi:10.1105/tpc.7.4.417
226. Nakamura Y, Umemoto T, Takahata Y, Komae K, Amano E, Satoh H (1996) Changes in structure of starch and enzyme activities affected by sugary mutations in developing rice endosperm. Possible role of starch debranching enzyme (R-enzyme) in amylopectin biosynthesis. Physiol Plant 97:491-498. doi:10.1111/j.1399-3054.1996.tb00508.x

227. Burton RA, Jenner H, Carrangis L, Fahy B, Fincher GB, Hylton C, Laurie DA et al (2002) Starch granule initiation and growth are altered in barley mutants that lack isoamylase activity. Plant J 31:97-112. doi:10.1046/j.1365-313X.2002.01339.x

228. Bustos R, Fahy B, Hylton CM, Seale R, Nebane NM, Edwards A, Martin C, Smith AM (2004) Starch granule initiation is controlled by a heteromultimeric isoamylase in potato tubers. Proc Natl Acad Sci 101:2215-2220. doi:10.1073/pnas. 0305920101

229. Mouille G, Maddelein ML, Libessart N, Talaga P, Decq A, Delrue B, Ball S (1996) Preamylopectin processing: a mandatory step for starch biosynthesis in plants. Plant Cell 8:1353-1366. doi:10.1105/tpc.8.8.1353

230. Sumner J, Somers G (1944) The water-soluble polysaccharides of sweet corn. Arch Biochem 4:7-9

231. Fujita N, Hanashiro I, Suzuki S, Higuchi T, Toyosawa Y, Utsumi Y, Itoh R, Aihara S, Nakamura Y (2012) Elongated phytoglycogen chain length in transgenic rice endosperm expressing active starch synthase IIa affects the altered solubility and crystallinity of the storage $\alpha$-glucan. J Exp Bot 63:5859-5872. doi:10.1093/jxb/ers235

232. Ball S, Guan HP, James M, Myers A, Keeling P, Mouille G, Buléon A, Colonna P, Preiss J (1996) From glycogen to amylopectin: a model for the biogenesis of the plant starch granule. Cell 86:349-352

233. Zeeman SC, Umemoto T, Lue WL, Au-Yeung P, Martin C, Smith AM, Chen J (1998) A mutant of Arabidopsis lacking a chloroplastic isoamylase accumulates both starch and phytoglycogen. Plant Cell 10:1699-1712

234. Lin Q, Facon M, Putaux JL, Dinges JR, Wattebled F, D’Hulst C, Hennen-Bierwagen TA, Myers AM (2013) Function of isoamylase-type starch debranching enzymes ISA1 and ISA2 in the Zea mays leaf. New Phytol 200:1009-1021. doi:10.1111/ nph. 12446

235. Sundberg M, Pfister B, Fulton D, Bischof S, Delatte T, Eicke S, Stettler M, Smith SM, Streb S, Zeeman SC (2013) The heteromultimeric debranching enzyme involved in starch synthesis in Arabidopsis requires both Isoamylase1 and Isoamylase2 subunits for complex stability and activity. PLoS One 8:e75223. doi:10.1371/journal.pone.0075223

236. Zeeman SC, Northrop F, Smith AM, Rees T (1998) A starchaccumulating mutant of Arabidopsis thaliana deficient in a chloroplastic starch-hydrolysing enzyme. Plant J 15:357-365

237. Facon M, Lin Q, Azzaz AM, Hennen-Bierwagen TA, Myers AM, Putaux J-L, Roussel X, D'Hulst C, Wattebled F (2013) Distinct functional properties of isoamylase-type starch debranching enzymes in monocot and dicot leaves. Plant Physiol 163:1363-1375. doi:10.1104/pp.113.225565

238. Hussain H, Mant A, Seale R, Zeeman S, Hinchliffe E, Edwards A, Hylton C et al (2003) Three isoforms of isoamylase contribute different catalytic properties for the debranching of potato glucans. Plant Cell 15:133-149. doi:10.1105/tpc.006635. 1901

239. Deschamps P, Moreau H, Worden AZ, Dauvillée D, Ball SG (2008) Early gene duplication within chloroplastida and its correspondence with relocation of starch metabolism to chloroplasts. Genetics 178:2373-2387. doi:10.1534/genetics. 108.087205

240. Utsumi Y, Nakamura Y (2006) Structural and enzymatic characterization of the Isoamylase1 homo-oligomer and the 
Isoamylase1-Isoamylase2 hetero-oligomer from rice endosperm. Planta 225:75-87. doi:10.1007/s00425-006-0331-z

241. Kubo A, Colleoni C, Dinges JR, Lin Q, Lappe RR, Rivenbark JG, Meyer AJ et al (2010) Functions of heteromeric and homomeric isoamylase-type starch-debranching enzymes in developing maize endosperm. Plant Physiol 153:956-969. doi:10.1104/pp.110.155259

242. Sim L, Beeren SR, Findinier J, Dauville D, Ball SG, Henriksen A, Palcic MM (2014) Crystal structure of the Chlamydomonas starch debranching enzyme isoamylase ISA1 reveals insights into the mechanism of branch trimming and complex assembly. J Biol Chem 289:22991-23003. doi:10.1074/jbc.M114.565044

243. Utsumi Y, Utsumi C, Sawada T, Fujita N, Nakamura Y (2011) Functional diversity of isoamylase oligomers: the ISA1 homooligomer is essential for amylopectin biosynthesis in rice endosperm. Plant Physiol 156:61-77. doi:10.1104/pp.111. 173435

244. Luo J, Ahmed R, Kosar-Hashemi B, Larroque O, Butardo VM, Tanner GJ, Colgrave ML et al (2015) The different effects of starch synthase IIa mutations or variation on endosperm amylose content of barley, wheat and rice are determined by the distribution of starch synthase I and starch branching enzyme IIb between the starch granule and amyloplast stroma. Theor Appl Genet 128:1407-1419. doi:10.1007/s00122-015-2515-Z

245. Liu F, Romanova N, Lee EA, Ahmed R, Evans M, Gilbert EP, Morell MK, Emes MJ, Tetlow I (2012) Glucan affinity of starch synthase IIa determines binding of starch synthase I and starch branching enzyme $\mathrm{IIb}$ to starch granules. Biochem $\mathbf{J}$ 448:373-387. doi:10.1042/BJ20120573

246. Liu F, Ahmed Z, Lee EA, Donner E, Liu Q, Ahmed R, Morell MK, Emes MJ, Tetlow IJ (2012) Allelic variants of the amylose extender mutation of maize demonstrate phenotypic variation in starch structure resulting from modified protein-protein interactions. J Exp Bot 63:1167-1183. doi:10.1093/jxb/err341

247. Makhmoudova A, Williams D, Brewer D, Massey S, Patterson J, Silva A, Vassall KA et al (2014) Identification of multiple phosphorylation sites on maize endosperm starch branching enzyme IIb, a key enzyme in amylopectin biosynthesis. J Biol Chem 289:9233-9246. doi:10.1074/jbc.M114.551093

248. Kötting O, Pusch K, Tiessen A, Geigenberger P, Steup M, Ritte $G$ (2005) Identification of a novel enzyme required for starch metabolism in Arabidopsis leaves. The phosphoglucan, water dikinase. Plant Physiol 137:242-252. doi:10.1104/pp.104. 055954

249. Ritte G, Heydenreich M, Mahlow S, Haebel S, Kötting O, Steup M (2006) Phosphorylation of C6- and C3-positions of glucosyl residues in starch is catalysed by distinct dikinases. FEBS Lett 580:4872-4876. doi:10.1016/j.febslet.2006.07.085

250. Edner C, Li J, Albrecht T, Mahlow S, Hejazi M, Hussain H, Kaplan F et al (2007) Glucan, water dikinase activity stimulates breakdown of starch granules by plastidial beta-amylases. Plant Physiol 145:17-28. doi:10.1104/pp.107.104224

251. Kötting O, Santelia D, Edner C, Eicke S, Marthaler T, Gentry MS, Comparot-Moss S et al (2009) STARCH-EXCESS4 is a laforin-like phosphoglucan phosphatase required for starch degradation in Arabidopsis thaliana. Plant Cell 21:334-346. doi: $10.1105 /$ tpc. 108.064360

252. Santelia D, Kötting O, Seung D, Schubert M, Thalmann M, Bischof S, Meekins DA et al (2011) The phosphoglucan phosphatase Like Sex Four2 dephosphorylates starch at the C3position in Arabidopsis. Plant Cell 23:4096-4111. doi:10.1105/ tpc.111.092155

253. Silver DM, Kötting O, Moorhead GBG (2014) Phosphoglucan phosphatase function sheds light on starch degradation. Trends Plant Sci 19:471-478. doi:10.1016/j.tplants.2014.01.008
254. Hejazi M, Mahlow S, Fettke J (2014) The glucan phosphorylation mediated by $\alpha$-glucan, water dikinase (GWD) is also essential in the light phase for a functional transitory starch turnover. Plant Signal Behav 9:e28892. doi:10.4161/psb.28892

255. Nielsen TH, Wischmann B, Enevoldsen K, Moller BL (1994) Starch phosphorylation in potato tubers proceeds concurrently with de novo biosynthesis of starch. Plant Physiol 105:111-117

256. Mahlow S, Hejazi M, Kuhnert F, Garz A, Brust H, Baumann O, Fettke J (2014) Phosphorylation of transitory starch by $\alpha$-glucan, water dikinase during starch turnover affects the surface properties and morphology of starch granules. New Phytol 203:495-507. doi:10.1111/nph.12801

257. Skeffington AW, Graf A, Duxbury Z, Gruissem W, Smith AM (2014) Glucan, water dikinase exerts little control over starch degradation in Arabidopsis leaves at night. Plant Physiol 165:866-879. doi:10.1104/pp.114.237016

258. Shimoura S, Nagai M, Fukui T (1982) Comparative glucan specificities of two types of spinach leaf phosphorylase. J Biochem 91:703-717

259. Yu Y, Mu HH, Wasserman BP, Carman GM (2001) Identification of the maize amyloplast stromal $112-\mathrm{kD}$ protein as a plastidic starch phosphorylase. Plant Physiol 125:351-359. doi:10.1104/pp.125.1.351

260. Tiessen A, Nerlich A, Faix B, Hümmer C, Fox S, Trafford K, Weber H, Weschke W, Geigenberger P (2012) Subcellular analysis of starch metabolism in developing barley seeds using a non-aqueous fractionation method. J Exp Bot 63:2071-2087. doi:10.1093/jxb/err408

261. Satoh H, Shibahara K, Tokunaga T, Nishi A, Tasaki M, Hwang S-K, Okita TW et al (2008) Mutation of the plastidial alphaglucan phosphorylase gene in rice affects the synthesis and structure of starch in the endosperm. Plant Cell 20:1833-1849. doi:10.1105/tpc.107.054007

262. Hwang S-K, Nishi A, Satoh H, Okita TW (2010) Rice endosperm-specific plastidial alpha-glucan phosphorylase is important for synthesis of short-chain malto-oligosaccharides. Arch Biochem Biophys 495:82-92. doi:10.1016/j.abb.2009.12. 023

263. Higgins JE, Kosar-Hashemi B, Li Z, Howitt CA, Larroque O, Flanagan B, Morell MK, Rahman S (2013) Characterization of starch phosphorylases in barley grains. J Sci Food Agric 93:2137-2145. doi:10.1002/jsfa.6019

264. Kossmann J, Visser RGF, Müller-Röber BT, Willmitzer L, Sonnewald U (1991) Cloning and expression analysis of a potato cDNA that encodes branching enzyme: evidence for co-expression of starch biosynthetic genes. Mol Gen Genet 230:39-44. doi:10.1007/BF00290648

265. Ozbun JL, Hawker JS, Greenberg E, Lammel C, Preiss J (1973) Starch synthetase, phosphorylase, ADPglucose pyrophosphorylase, and UDPglucose pyrophosphorylase in developing maize kernels. Plant Physiol 51:1-5

266. Schupp N, Ziegler P (2004) The relation of starch phosphorylases to starch metabolism in wheat. Plant Cell Physiol 45:1471-1484. doi:10.1093/pcp/pch170

267. Dauvillée D, Chochois V, Steup M, Haebel S, Eckermann N, Ritte G, Ral JP et al (2006) Plastidial phosphorylase is required for normal starch synthesis in Chlamydomonas reinhardtii. Plant J 48:274-285. doi:10.1111/j.1365-313X.2006.02870.x

268. Subasinghe RM, Liu F, Polack UC, Lee EA, Emes MJ, Tetlow IJ (2014) Multimeric states of starch phosphorylase determine protein-protein interactions with starch biosynthetic enzymes in amyloplasts. Plant Physiol Biochem 83:168-179. doi:10.1016/j. plaphy.2014.07.016

269. Sonnewald U, Basner A, Greve B, Steup M (1995) A second L-type isozyme of potato glucan phosphorylase: cloning, 
antisense inhibition and expression analysis. Plant Mol Biol 27:567-576. doi:10.1007/BF00019322

270. Zeeman SC, Thorneycroft D, Schupp N, Chapple A, Weck M, Dunstan H, Haldimann P, Bechtold N, Smith AM, Smith SM (2004) Plastidial $\alpha$-glucan phosphorylase is not required for starch degradation in Arabidopsis leaves but has a role in the tolerance of abiotic stress. Plant Physiol 135:849-858. doi:10. 1104/pp.103.032631.1

271. Devin A (2010) Etablissement de l'implication des $\alpha$ - et $\beta$ amylases et des $\alpha$-glucanes phosphorylases au cours de la dégradation de l'amidon dans la feuille d'Arabidopsis thaliana. Dissertation, Université des Sciences et Technologies de Lille

272. Malinova I, Mahlow S, Alseekh S, Orawetz T, Fernie AR, Baumann O, Steup M, Fettke J (2013) Double knockout mutants of Arabidopsis grown under normal conditions reveal that the plastidial phosphorylase isozyme participates in transitory starch metabolism. Plant Physiol 164:907-921. doi:10.1104/pp.113. 227843

273. Weise SE, Schrader SM, Kleinbeck KR, Sharkey TD (2006) Carbon balance and circadian regulation of hydrolytic and phosphorolytic breakdown of transitory starch. Plant Physiol 141:879-886. doi:10.1104/pp.106.081174

274. Peng C, Wang Y, Liu F, Ren Y, Zhou K, Lv J, Zheng M et al (2014) FLOURY ENDOSPERM6 encodes a CBM48 domaincontaining protein involved in compound granule formation and starch synthesis in rice endosperm. Plant J 77:917-930. doi:10. 1111/tpj. 12444

275. Feike D, Seung D, Graf A, Bischof S, Ellick T, Coiro M, Soyk S, Eicke S, Mettler T, Lu KJ, Trick M, Zeeman SC, Smith AM (2016) A novel starch-granule-associated protein required for the control of starch degradation in Arabidopsis thaliana leaves. Plant Cell (accepted)

276. Han X, Wang Y, Liu X, Jiang L, Ren Y, Liu F, Peng C et al (2012) The failure to express a protein disulphide isomerase-like protein results in a floury endosperm and an endoplasmic reticulum stress response in rice. J Exp Bot 63:121-130. doi:10. 1093/jxb/err262

277. Wang Y, Ren Y, Liu X, Jiang L, Chen L, Han X, Jin M et al (2010) OsRab5a regulates endomembrane organization and storage protein trafficking in rice endosperm cells. Plant $\mathrm{J}$ 64:812-824. doi:10.1111/j.1365-313X.2010.04370.x
278. Matsushima R, Maekawa M, Kusano M, Kondo H, Fujita N, Kawagoe Y, Sakamoto W (2013) Amyloplast-localized SUBSTANDARD STARCH GRAIN4 protein influences the size of starch grains in rice endosperm. Plant Physiol 164:623-636. doi:10.1104/pp.113.229591

279. Matsushima R, Maekawa M, Fujita N, Sakamoto W (2010) A rapid, direct observation method to isolate mutants with defects in starch grain morphology in rice. Plant Cell Physiol 51:728-741. doi:10.1093/pcp/pcq040

280. Zhang L, Ren Y, Lu B, Yang C, Feng Z, Liu Z, Chen J et al (2015) FLOURY ENDOSPERM7 encodes a regulator of starch synthesis and amyloplast development essential for peripheral endosperm development in rice. J Exp Bot. doi:10.1093/jxb/ erv469

281. Wang JC, Xu H, Zhu Y, Liu QQ, Cai XL (2013) OsbZIP58, a basic leucine zipper transcription factor, regulates starch biosynthesis in rice endosperm. J Exp Bot 64:3453-3466. doi:10.1093/jxb/ert187

282. Fu F-F, Xue H-W (2010) Coexpression analysis identifies Rice Starch Regulator1, a rice AP2/EREBP family transcription factor, as a novel rice starch biosynthesis regulator. Plant Physiol 154:927-938. doi:10.1104/pp.110.159517

283. She K-C, Kusano H, Koizumi K, Yamakawa H, Hakata M, Imamura T, Fukuda M et al (2010) A novel factor FLOURY ENDOSPERM2 is involved in regulation of rice grain size and starch quality. Plant Cell 22:3280-3294. doi:10.1105/tpc.109. 070821

284. Streb S, Zeeman SC (2012) Starch metabolism in Arabidopsis. In: The Arabidopsis Book, Number 9. The American Society of Plant Biologists. doi:10.1199/tab.0160

285. Emanuelsson O, Nielsen H, von Heijne G (1999) ChloroP, a neural network-based method for predicting chloroplast transit peptides and their cleavage sites. Protein Sci 8:978-984. doi:10. 1110/ps.8.5.978

286. McDonnell AV, Jiang T, Keating AE, Berger B (2006) Paircoil2: improved prediction of coiled coils from sequence. Bioinformatics 22:356-358. doi:10.1093/bioinformatics/bti797

287. Letunic I, Doerks T, Bork P (2014) SMART: recent updates, new developments and status in 2015. Nucleic Acids Res 43:D257-D260. doi:10.1093/nar/gku949 